\title{
ASSESSMENT OF NURSING PRACTICE, COMPETENCES AT CLINICAL TO PREVENT DECUBITUS ULCERS AT TERTIARY CARE HOSPITAL LAHORE PAKISTAN
}

\author{
Fazilat Ul Noor, Reg \# PBSNO2183003 \\ Lahore School of Nursing \\ The University of Lahore \\ Lahore, Pakistan \\ mahinoor055@gmail.com \\ Kousar Parveen, Assistant Professor \\ Lahore School of Nursing \\ The University of Lahore \\ Lahore, Pakistan \\ Kousar.parveen@uol.lsn.edu.pk
Muhammad Hussain, Assistant Professor
Lahore School of Nursing
The University of Lahore
Lahore, Pakistan
mhussainsial@gmail.com
Muhammad Afzal, associate professor
Lahore School of Nursing
The University of Lahore
Lahore, Pakistan
mafzalaku@gmail.com \\ Prof. Dr. Syed Amir Gilani \\ Lahore School of Nursing \\ The University of Lahore \\ Lahore, Pakistan \\ profgilani@gmail.com
}

\begin{abstract}
Introduction: Globally higher-than-anticipated decubitus ulcer rates normally viewed as a quality of care indicator. Numerous nations at present has no national strategies for pressure ulcer hazard appraisal, anticipation, and treatment. Decubitus ulcer lead to torment and distress for patients and furthermore cause disease, defer healing, increment duration of patient's stay in hospital, and may prompt sickness and even expiry Methodology: quantitative observational descriptive study design was used to assess the nursing practice, competences at clinical to prevent decubitus ulcers at tertiary care hospital, data was collected through the standardized checklist regarding decubitus ulcer prevention. The check consists of 27 items. Results: The findings of this study revealed that there are poor practices of nurses regarding prevention of decubitus of critically ill patients. Conclusion: This study was conducted to assess level of nurses' practice towards pressure ulcer prevention. Generally, the study showed that: Nurses' overall practice regarding pressure ulcer prevention was poor. Education can bring a change in individual behavior so change in knowledge can influence the practices. So, nurses need to get continuing education and training about pressure ulcer prevention that will enhance their knowledge and practices. Further researches about pressure ulcer prevention are needed.
\end{abstract}

Key words: Decubitus ulcer, Practice, Prevention, Patient.

DOI: $10.7176 / \mathrm{JHMN} / 74-09$

Publication date:May $31^{\text {st }} 2020$ 


\section{CHAPTER - I \\ INTRODUCTION}

Background: Globally higher-than-anticipated decubitus ulcer rates normally viewed as a quality of care indicator. Numerous nations at present has no national strategies for pressure ulcer hazard appraisal, anticipation, and treatment (Esan, Fasoro, Ojo, \& Obialor, 2018). Decubitus ulcer lead to torment and distress for patients and furthermore cause disease, defer healing, increment duration of patient's stay in hospital, and may prompt sickness and even expiry (Nasreen, Afzal, \& Sarwar, 2017).

World stop pressure ulcer day demonstrated that about 700,000 patients were influenced by pressure ulcers every year. Around 186,617 patients build up another decubitus ulcer in intense consideration settings every year. This has indicated that in the year January 2012 to December 2013 somewhere in the range of 4 and $6 \%$ of patients in intense consideration settings and more than $5-10 \%$ of patients in intense consideration had no decubitus ulcers. decubitus ulcers are responsible for $2 \%$ of preventable expiry (Dilie \& Mengistu, 2015).

Decubitus ulcer happens as a result of long time pressure on the skin or when the skin is entangled between the hard surface and the bone (Mahalingam et al., 2014). Despite progression in medication and nursing; pressure ulcers stay one of the significant reasons for horribleness and mortality around the world. Around 60,000 individuals passed away due to entanglements of decubitus ulcer around the world (Teague et al., 2011). Decubitus ulcers bring about high human and financial expenses with a lower personal satisfaction and huge pain, reduced useful self-sufficiency, genuine contaminations, and longer health care setup stay with additional expenses to the hospital (Coyer \& Tayyib, 2017).

Patients endure with agony and inconvenience due to pressure ulcer and furthermore cause draw out sickness, postpone recovery, increment patient's hospital stay, and may prompt incapacity and even expiry (Nuru, Zewdu, Amsalu, \& Mehretie, 2015). Nursing staff practices toward pressure ulcer counteraction were not dependable in light of the fact that nurses organized it exceptionally low level that is a result of their insufficient information about the genuine outcome of decubitus ulcer dangers. They had no entrance and modern information on proof base practices (Mwebaza, Katende, Groves, \& Nankumbi, 2014).

Presently days if a patient built up a decubitus ulcer during his hospitalization it will show the low quality of nursing care. Despite the fact that to keep a patient from a weight ulcer are the obligation of all medicinal services proficient however fundamentally are the duty of the individuals who are associated with direct patient consideration and nurses are forefronts for giving weight ulcer avoidance care (Kaddourah, Abu-Shaheen, \& Al-Tannir, 2016).

Nursing staff poor information and abilities in pressure ulcer anticipation contributes essentially to the advancement or compounding of decubitus ulcers and this is might be directed to more confusions, Therefore, medical caretakers require standard preparing and instruction right now practice. There is a gap between nursing staff information on pressure ulcer anticipation and the usage of this information as indicated by appropriate guidelines in their practices. Medical caretakers have great information with respect to pressure ulcers yet they have poor works on in regards to pressure ulcers avoidance (Shrestha, 2017).

Medicinal services experts can recognize individuals who are in danger of creating pressure ulcers via doing a decubitus ulcer hazard appraisal. By doing this inside 6 hours of when an individual is admitted to hospital or a consideration home with nursing, those in danger or high danger of creating pressure ulcers can be recognized immediately. Following up on the consequences of the hazard evaluations permits human services experts to offer safeguard treatment to individuals in danger, assisting with lessening the quantity of individuals building up a decubitus ulcer and guaranteeing persistent wellbeing (McInnes et al., 2015).

Seriousness in pressure ulcer are possibly perilous conditions and patients request outstanding consideration. Nursing works on during care of patients with pressure ulcer are basic for the prosperity of patients and human services laborer. nurses are assuming as a significant job during care and counteraction of patient from pressure ulcer. This consideration ought to be given by learned and able nurses following explicit rule or conventions that will decrease the event of decubitus ulcer and difficulties (Gage, 2015). 
At whatever point an individual has a decubitus ulcer chance appraisal that shows they are at high danger of creating pressure ulcers, a subsequent skin evaluation ought to be completed. A clinical appraisal of the skin by a human service proficient, considering any agony revealed by the individual, may anticipate the improvement of a decubitus ulcer. The aftereffects of the skin appraisal can be utilized to offer appropriate protection intercessions to individuals who are at high danger of creating pressure ulcers. A skin evaluation should be rehashed at whatever point an individual is recognized as at high hazard because of a pressure ulcer chance appraisal, to assess any progressions to the skin and to guarantee patient and administration client wellbeing (Stansby, Avital, Jones, \& Marsden, 2014).

Individuals who are in danger of creating pressure ulcers ought to get guidance about changing their position routinely, how changing position can help diminish the danger of building up a decubitus ulcer, and how as often as possible they should change position (as per their individual danger of building up a pressure ulcer) (Stephens \& Bartley, 2018). Healthcare experts guarantee that they give individuals who are at high danger of creating pressure ulcers, custommade data on the most proficient method to forestall them.

Nourishing hardship and inadequate dietary admission are the key hazard factors for the improvement of decubitus ulcers and hindered wound recuperating. Impromptu weight reduction is a significant hazard factor for ailing health and decubitus ulcer advancement. Problematic nourishment meddles with the capacity of the invulnerable framework, collagen blend, and rigidity. No research center test can precisely characterize a person's healthful status. Satisfactory liquid admission is important to help the blood stream to injured tissues and to forestall extra breakdown of the skin (Saghaleini et al., 2018).

Problem statement: Now days if a patient built up a decubitus ulcer during his hospitalization it will demonstrate the low quality of nursing care. World stop pressure ulcer day indicated that almost 700,000 patients were influenced by pressure ulcers every year. Around 186,617 patients build up new decubitus ulcer in intense consideration settings every year (Dilie \& Mengistu, 2015).

Consequently, there is proof that administration and anticipation of patient need a novel assortment of information and aptitudes from a capable multidisciplinary colleague particularly the medical caretaker, and explicit decubitus ulcer preventive rules ought to be produced for forestalling pressure ulcer. The real need to do the investigation is to survey the act of medical caretakers with respect to counteraction of patient from pressure ulcer.

Purpose of the study: The motivation behind the examination is to evaluate the nursing practice, capabilities at clinical to prevent decubitus ulcers at tertiary care hospital Lahore Pakistan.

\section{Research questions:}

Hypothesis

- What is the practice, competences of nurses at clinical to prevent decubitus ulcers at tertiary care hospital?

Alternative hypothesis:

- Nurses practices may have effect to prevent decubitus ulcers at tertiary care hospital.

Null hypotheses:

- Nurses practices may have effect to prevent decubitus ulcers at tertiary care hospital.

Conceptual definition

Practices: "The application of rules and knowledge that leads to action"(Badran, 1995)

Decubitus ulcer: Decubitus ulcers can be defined as when localized tissue gets deprived of circulation due to soft tissue compressed between external surfaces and bony prominence for prolong time (Black et al., 2007).

\section{Operational definition}

Practices: Standard guidelines follow/use by nurses to prevent decubitus ulcer working in medical and surgical department of tertiary care hospital Lahore.

Decubitus ulcer: patient admitted in medical or surgical department are suffer from the deprivement of circulation due to tissue compression between external surfaces and bony prominence for long time at tertiary care hospital Lahore Pakistan.

Variables of Study:

\section{Independent variable;}


- $\quad$ Practices

\section{Dependent variable;}

- Decubitus ulcer

\section{Limitation/ Scope of the study}

- Investigation discoveries will be restricted and can't be summed up generally that the little example and chose from one topographical zone in Pakistan.

- The extent of the investigation will be likewise restricted not utilized benchmark group.

\section{CHAPTER - II REVIEW OF LITERATURE}

An examination led in 2018 to survey the nursing staff with respect to anticipation of decubitus ulcer and results uncovered that the overall, $64.4 \%$ nurses had right decubitus ulcer information and $74.4 \%$ had an uplifting demeanor toward forestalling pressure ulcers. In any case, $62.2 \%$ couldn't help contradicting ordinary rescreening of patients whom they esteemed not in danger of creating pressure ulcer, and $77.8 \%$ accepted decubitus ulcer counteraction ought to be the joint duty of the two medical caretakers and family members of the patients. Along these lines, most of the 90 nurses knew the variables answerable for decubitus ulcers and how to forestall them (Esan et al., 2018).

In Pakistan, Lahore area an examination led in tertiary consideration hospital with respect to evaluation of nursing staff works on in regards to decubitus and results uncovered that $82.6 \%$ have poor practices, $7.1 \%$ have reasonable practices and $10.3 \%$ have great acts of weight ulcer counteraction. Medical caretaker's professional training has a huge relationship with their practices and information toward pressure ulcer anticipation. Nurses in general information and practices toward pressure ulcer are poor. Working experience had a critical relationship with nurses practices and information at Lahore general hospital (Nasreen et al., 2017).

Another investigation directed in Pakistan, Peshawar area in 2016 with respect to the evaluation of medical caretaker's practices for the avoidance of decubitus ulcer and results uncovered that the acts of nurses in regards to the "consistently" explanations was $45.4 \%$ while of the "never" proclamation was $42.4 \%$. The scope of most elevated and least reacted "consistently" proclamation was $57 \%$ and $18 \%$. Study finding additionally shows that nursing staff however had sufficient information with respect to pressure ulcer avoidance yet the absence of legitimate strategies and rules, absence of proof based practice and absence of in-administration trainings prompted negative mentality and inappropriate practice among medical caretakers in Khyber Teaching Hospital in regards to pressure ulcers counteraction (Muhammad, Ahmad, Khan, Ali, \& Muhammad).

In another examination author recommended that the factually noteworthy decrease in the predominance of Pressure ulcer to $7.53 \%(\mathrm{p}<.001)$. The online instructional exercise improved staff information level with a measurably fundamentally higher mean post-test score $(n=80)$. Thirty-five bleeding edge staff shared their viewpoints of the decubitus ulcer Prevention Program with "it's very a blend of everything" and "there's a distinction between what's required and what's accessible" as the fundamental subjects (Martin et al., 2017).

In 2019, an examination directed for the appraisal of weight ulcer care execution of nurses was evaluated 3.99 out of 5. Execution level in "wound consideration: debridement"; "torment control"; "anticipation healthy skin"; "incontinence the executives"; "supporting surface"; and "sustenance in pressure ulcer avoidance and treatment" was underneath normal. Enthusiasm for pressure ulcer care $(\beta=.28, p=<.001)$, the fundamental decubitus ulcer administrator in a ward being an injury, ostomy, self-control nurture $(\beta=.22, \mathrm{p}=.013)$, and an establishment with a nursing practice rule for pressure ulcer care $(\beta=.16, \mathrm{p}=.02)$ were recognized as noteworthy variables influencing a decent decubitus ulcer care execution (Kim, Yoo, Nho, \& Ju, 2019).

Risk assessment undertaken on admission: Service suppliers (health care and care homes with nursing) guarantee that frameworks are set up for human services experts to be prepared in surveying pressure ulcer chance, and that they do and report a decubitus ulcer chance evaluation inside 6 hours of an individual being admitted to medical clinic or 
a consideration home with nursing. Hospital services experts guarantee that they realize how to survey an individual's decubitus ulcer hazard, and that they complete and archive a decubitus ulcer chance evaluation inside 6 hours of an individual being admitted to emergency clinic or a consideration home with nursing (Gage, 2015).

Skin assessment: Service suppliers (essential consideration, community care, clinics and care homes with nursing) guarantee that social insurance experts are prepared to complete skin evaluations, and that they do a skin appraisal if an individual is recognized as high danger of creating pressure ulcers. Social insurance experts guarantee that they realize how to complete a skin evaluation, and that they do a skin appraisal if an individual in their consideration is recognized as high danger of creating pressure ulcers. Cleaning of the skin, least power and rubbing during cleaning, use of saturating operators, least introduction to dampness, utilization of boundary against dampness, skin assurance during moves are productive mediations for pressure ulcer avoidances (Stansby et al., 2014)

Repositioning: Repositioning, where the individual moves into an alternate situation in a seat or bed, expects to diminish or stop pressure on the zone in danger. To improve quiet understanding, wellbeing and social consideration experts ought to inform individuals in danger regarding creating pressure ulcers (or their vocations, as suitable) about the significance of continuous repositioning, and that it might assist with forestalling pressure ulcers. The recurrence of repositioning prompted ought to be fitting for the distinct individual and their desires and needs. For security reasons, repositioning is prescribed no less than like clockwork for grown-ups in danger, and at regular intervals for grown-ups at high hazard. heels lifted to diminish pressure, limiting the period in which the leader of the bed tilted in excess of 30 degrees, trained how to reposition themselves when sitting on the seat and when sitting on the seat position changed each hour or moved to bed are fundamentals to forestall ulcer (Stephens \& Bartley, 2018).

Using devices to prevent contact between bony prominences: Pressure redistribution equipment's work by decreasing or redistributing weight, grating or shear powers. equipment's incorporate high-particular sleeping cushions, pressure redistribution pads and hardware that offloads heel pressure. The sort of equipment's an individual need will rely upon their conditions, for instance, their portability, the consequences of the skin appraisal, their degree of hazard, the site that is in danger, the individual's weight and the individual's general wellbeing. Utilizing pressure redistribution equipment's as quickly as time permits can forestall pressure ulcers creating and help to treat them on the off chance that they do emerge, guaranteeing persistent wellbeing and improving the experience of individuals at high danger of weight ulcers. Persistent activated (where conceivable) Use of weight assuaging bedding and utilization of weight alleviating equipment's on seats (Ashour, 2019)

Nutritional assessment: The National Institute for Health and Care Excellence expresses that satisfactory hazard evaluation of pressure ulcer advancement, including the job of unhealthiness, improves care. Satisfactory sustenance is indispensable for the anticipation of weight ulcers and lack of healthy sustenance can block recuperating when pressure ulcers have created. The danger of lack of healthy sustenance ought to be evaluated with a perceived device, for example, the Malnutrition Universal Screening Tool, and fitting treatment plans ought to be drawn up for patients distinguished as being in danger of failing health to improve their dietary state. Moreover, helped with eating and drinking and Recording of healthful appraisal of patients assumes a significant job (Taylor, 2017).

Support staff given information on the prevention of pressure sores: Many decubitus ulcers are preventable. A great part of the deterrent consideration required happens in an individual's own home and should be conveyed routinely to guarantee persistent security. Social insurance experts should offer data to individuals at high danger of creating pressure ulcers (and their vocations, as fitting) about precaution care that may prevent pressure ulcers from creating. To improve tolerant experience, data about forestalling pressure ulcers ought to be suitable to the distinct individual and their professions. Data ought to incorporate the causes and indications of weight ulcers and how they influence wellbeing and personal satisfaction. It ought to likewise incorporate an exhibit of how to utilize gear that might be provided, and what individuals can do to help forestall pressure ulcers from creating (Shanley et al., 2019). 


\section{Objectives}

\section{General objective:}

- To assess the nurse's practices for counteraction of decubitus ulcer among patients in tertiary care hospital Lahore.

\section{Specific objectives:}

- To assess the nurse's practices regarding risk assessment for anticipation of decubitus ulcer among patients in tertiary care hospital Lahore.

- To assess the nurse's practices regarding positioning for anticipation of decubitus ulcer among patients in tertiary care hospital Lahore.

- To assess the nurse's practices regarding use of devices for anticipation of decubitus ulcer among patients in tertiary care hospital Lahore.

- To assess the nurse's practices regarding skin assessment for anticipation of decubitus ulcer among patients in tertiary care hospital Lahore.

- To assess the nurse's practices regarding nutrition for anticipation of decubitus ulcer among patients in tertiary care hospital Lahore.

\section{Significance of the study}

Patient: who conceded for the most part is profoundly helpless to pressure ulcer. In this manner, the use of widespread safety measures, protect the patient from pressure ulcer. it also promotes patient safety and decrease risk.

Nurse: subsequently, assessment level of nurses' practice about prevention of pressure ulcer is vital action to control and prevent pressure ulcer. In this way nurses will understand their weakness and tried to adopt standard guide line in results their knowledge and skills will be improved.

Organization: The Finding of the examination may be useful for the association to build up the methodologies to control superfluous of pressure ulcer through instructional meeting, workshop, and class in result at last this will improve the workplace and nature of care. It will be appropriate for the administration to find a way to locate the powerless components. In results the quality of care will be improved.

Policy maker: This mindfulness will help the strategy creator to plan methodologies and set in motion to improve the workplace.

Future researcher: The aftereffect of this investigation will provide guidance to the future analyst to use this examination as a writing and direction. Moreover, study will assist them with identifying the investigation hole. The discoveries of the examination can be utilized as optional information for future research researchers. 
Study Design:

\section{CHAPTER - III \\ MATERIAL AND METHODS}

Observational descriptive design was use to assess the nursing practice, competences at clinical to prevent decubitus ulcers at tertiary care hospital Lahore Pakistan.

\section{Study site:}

The study was conducted in urban area located at Lahore, Pakistan.

\section{Study Setting:}

The study was conducted medical and surgical units of Jinnah hospital Lahore.

\section{Study Duration:}

The Study span was 4 months from February, 2020 to May, 2020.

Study Population:

The examination population was all charge nurses working in medical and surgical units of Jinnah hospital.

\section{Inclusion Criteria:}

- All charge nurses working in medical and surgical units of Jinnah hospital for a half year before the beginning of data collection.

- Willing to participate

\section{Exclusion Criteria:}

- Nurses working in medical and surgical units, who were not involved in direct patient care e.g. Head nurses, Clinical Instructors and Nurse Managers and nurses who have worked for less than six months in the Burns Unit.

- $\quad$ Not willing to participate

Sampling Technique:

Data was collected by convenient sampling technique from selected sample.

\section{Sample Size:}

Sample size was calculated by using "Selvin's formula".

$\mathrm{n}=\mathrm{N} / 1+(\mathrm{N})(\mathrm{E})^{2}$

The population for this study is 240 .

$\mathrm{N}=$ Population, $\mathrm{n}=$ Sample size, $\mathrm{E}=5 \%$ Margin of mistake Confidence interim $95 \%$

$\mathrm{n}=\mathrm{N} / 1+(\mathrm{N})(\mathrm{E}) 2$

$\mathrm{n}=240 / 1+(240)(0.05) 2$

$\mathrm{n}=240 / 1+(240)(0.0025)$

$n=240 / 1+.6$

$\mathrm{n}=240 / 1.6$

$\mathrm{n}=150$

The sample size for this study will be 150 .

\section{Ethical Consideration;}

Composed consent was taken from the Ethical board of University of Lahore. Authorization was taken from the Nursing director of Jinnah hospital to lead inquire about investigation. All members were educated about the motivation behind the examination. All data and gathered information were kept classified by head examiner printed version in lock. Classification of delicate duplicate will be kept up by a coding. The subject was educated that there are no drawbacks or hazard on the techniques of the investigation.

\section{Data collection procedure:}

After endorsement survey was given to the nurses to evaluate the information and watch the attendant's practices over a time of 01 months beginning from March, 2020. The chose units was visited on regular routine and nurses will approached during morning, night and night shifts. 


\section{Data Collection Instrument and Tools:}

A well-adapted check was used to measure the practices in this study and it consists of two sections.

Section A: section A consists of demographic data such as gender, age, type of the wards, length of stay, history of hospitalization and history of pressure ulcers.

Section B: section "B" is a checklist including, Risk assessment undertaken on admission, skin assessment, nutritional assessment, positioning and use of devices. Check list will use to assess the practices of nurses working in burn units.

\section{Data Analysis Method:}

The data was analyzing the data by SPSS version 16. Statistical analysis of the study was descriptive. The study sample will be characterized by using a measure of central tendency (mean, median, and mode).

\section{CHAPTER - IV RESULTS}

This study is conducted at Jinnah hospital to assess the nurses' practice, competences at clinical to prevent decubitus ulcers. The result of this study distributed into two sections, first section is statistics of demographic factors of patients admitted in hospital acquiring care regarding decubitus ulcer prevention from nurses and second is frequency and statistics of checklist items regarding prevention of decubitus ulcer and assessment the nurse's practices accordingly. Section A: Table 1 shows that the frequency of demographics includes gender, age, history of hospitalization, type of the wards, length of stay (days), history of pressure ulcers and presence of pressure ulcers (at time of study) of the 150 participants and the results revealed that the gender of the participants was found $80(53.3 \%)$ male and $70(46.7 \%)$ were female. Age of participants was found minimum 21 to highest 60, participant's age group 21-30 years frequency was $11(7.3 \%)$, moderately $44(29.3 \%)$ participants were belong to age group 31-40 years and $33(22.1 \%)$ were fall in age group $41-50$ years and majority 62 (42.3\%) were 51-60-year-old. Only 37 (24.7\%) participants have not previously hospitalised and majority $113(75,3 \%)$ previously hospitalised. Participants' type of the ward as expected was majority $89(59.3 \%)$ admitted in critical care units, only $23(15.3 \%)$ admitted in medical wards and 38 (25.3\%) were admitted in surgical ward. The length of stay (days) in hospital of the participants was found as $22(14.3 \%)$ were stayed in hospital for 1-10 days, 43 (28.3\%) were stay for 11-20 days, majority 53 (35.2\%) were stay 21-30 days and $32(21.2 \%)$ stay for 31 or more than 31 days. Assessment regarding history of pressure ulcer and results revealed that majority $78(52 \%)$ have not previous history of ulcer and $72(48 \%)$ have previous history of ulcer. Observation regarding presence of pressure ulcers, and results revealed that $92(61.3 \%)$ have pressure ulcer at the time of study and $58(38.7 \%)$ have not ulcer at the time of study.

\section{Demographic data frequency}

\begin{tabular}{|c|c|c|c|}
\hline \multicolumn{2}{|r|}{ Variable } & Frequency & Valid Percent \\
\hline Gender & $\begin{array}{l}\text { Male } \\
\text { Female } \\
\text { Total }\end{array}$ & $\begin{array}{l}80 \\
70 \\
\mathbf{1 5 0}\end{array}$ & $\begin{array}{l}53.3 \% \\
46.7 \% \\
100 \%\end{array}$ \\
\hline Age & $\begin{array}{l}21-30 \text { years } \\
31-40 \text { years } \\
41-50 \text { years } \\
51-60 \text { years } \\
\text { Total }\end{array}$ & \begin{tabular}{l|l|}
11 \\
44 \\
33 \\
62 \\
150 \\
\end{tabular} & $\begin{array}{l}7.3 \% \\
29.3 \% \\
22.1 \% \\
42.3 \% \\
100 \% \\
\end{array}$ \\
\hline $\begin{array}{l}\text { History of } \\
\text { hospitalization }\end{array}$ & $\begin{array}{l}\text { Previously hospitalised } \\
\text { Not Previously hospitalised } \\
\text { Total }\end{array}$ & $\begin{array}{l}113 \\
37 \\
\mathbf{1 5 0}\end{array}$ & $\begin{array}{l}75.3 \% \\
24.7 \% \\
100 \%\end{array}$ \\
\hline Type of the wards & $\begin{array}{l}\text { Medical } \\
\text { Surgical } \\
\text { Critical Care Unit } \\
\text { Total }\end{array}$ & $\begin{array}{l}23 \\
38 \\
89 \\
\mathbf{1 5 0} \\
\end{array}$ & $\begin{array}{l}15.3 \% \\
25.3 \% \\
59.3 \% \\
100 \% \\
\end{array}$ \\
\hline Length of stay (days) & $1-10$ Days & 22 & $14.3 \%$ \\
\hline
\end{tabular}




\begin{tabular}{|l|l|l|l|}
\hline & $11-20$ Days & 43 & $28.3 \%$ \\
& $21-30$ Days & 53 & $35.2 \%$ \\
& 31 or more than 31 days & 32 & $21.2 \%$ \\
& Total & $\mathbf{1 5 0}$ & $\mathbf{1 0 0} \%$ \\
\hline \multirow{2}{*}{$\begin{array}{l}\text { History of pressure } \\
\text { ulcers }\end{array}$} & No previous ulcers History & 78 & $52 \%$ \\
& History of previous ulcers & 72 & $48 \%$ \\
\hline $\begin{array}{l}\text { Presence of pressure } \\
\text { ulcers (at time of } \\
\text { study) }\end{array}$ & Total & $\mathbf{1 5 0}$ & $\mathbf{1 0 0}$ \\
\hline & Uresent & 92 & $61.3 \%$ \\
\hline & Total & 58 & $38.7 \%$ \\
\hline
\end{tabular}

\section{Table 1}

Figure 1 shows that the age of participants and results revealed that minimum 21 to highest 60 , participant's age group 21-30 years frequency was $11(7.3 \%)$, moderately $44(29.3 \%)$ participants were belong to age group 31-40 years and $33(22.1 \%)$ were fall in age group $41-50$ years and majority $62(42.3 \%)$ were 51-60-year-old.
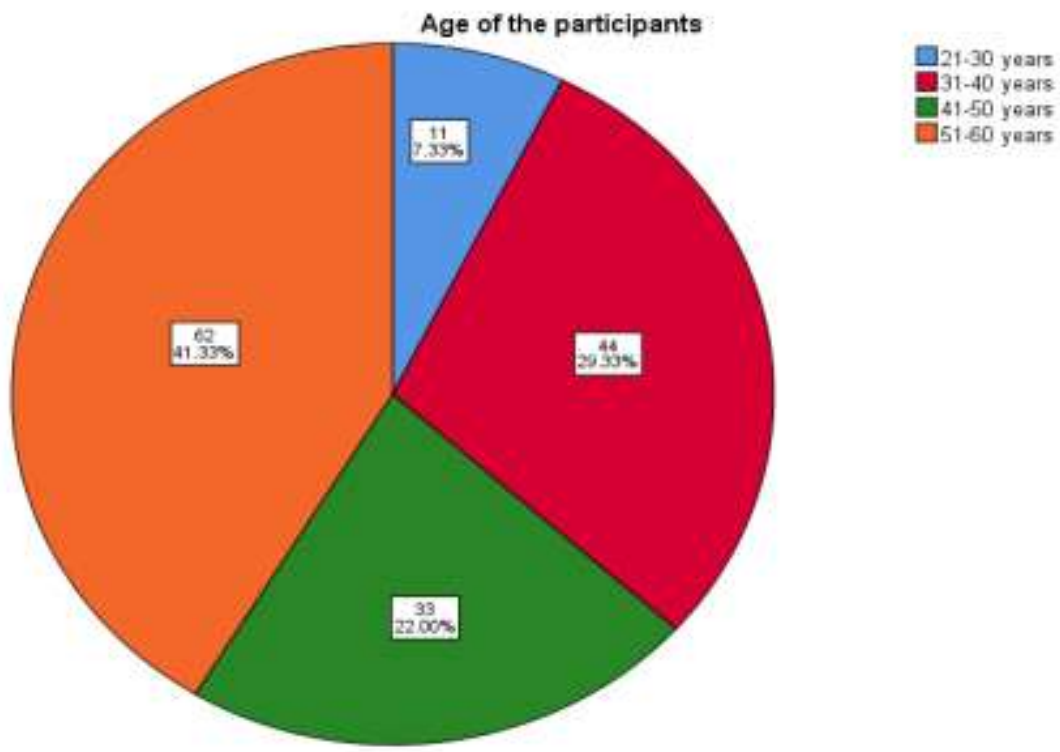

Figure 1

Figure 2 shows that gender of the participants and results revealed that the gender of the participants was found 80 $(53.3 \%)$ male and $70(46.7 \%)$ were female. 


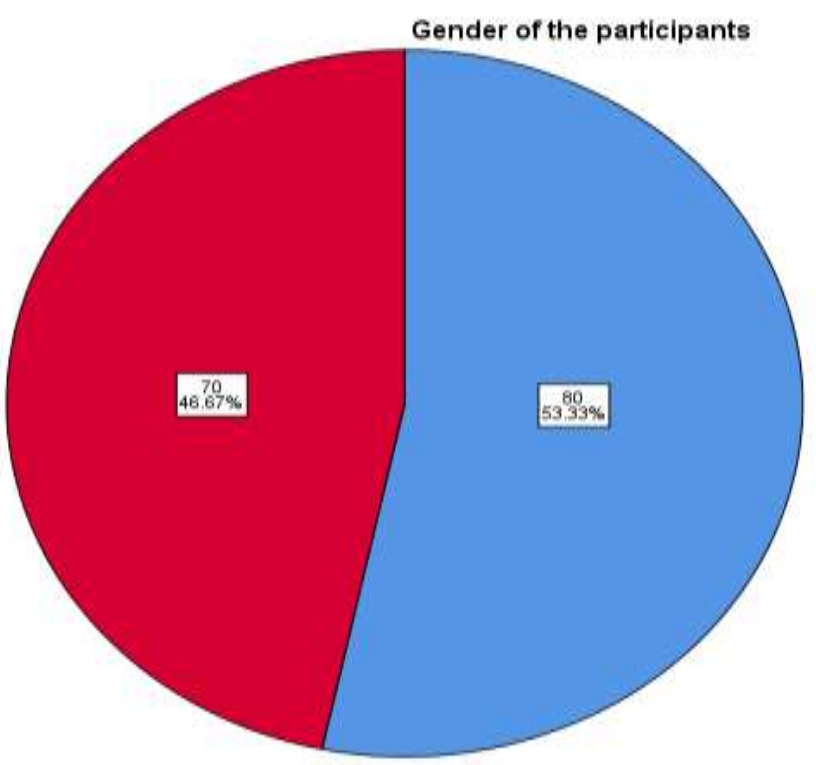

Male

Figure 2

Figure 3 shows that the type of ward which in the participants admitted and results revealed that only 37 (24.7\%) participants have not previously hospitalised and majority $113(75,3 \%)$ previously hospitalised. Participants' type of the ward as expected was majority $89(59.3 \%)$ admitted in critical care units, only $23(15.3 \%)$ admitted in medical wards and $38(25.3 \%)$ were admitted in surgical ward.

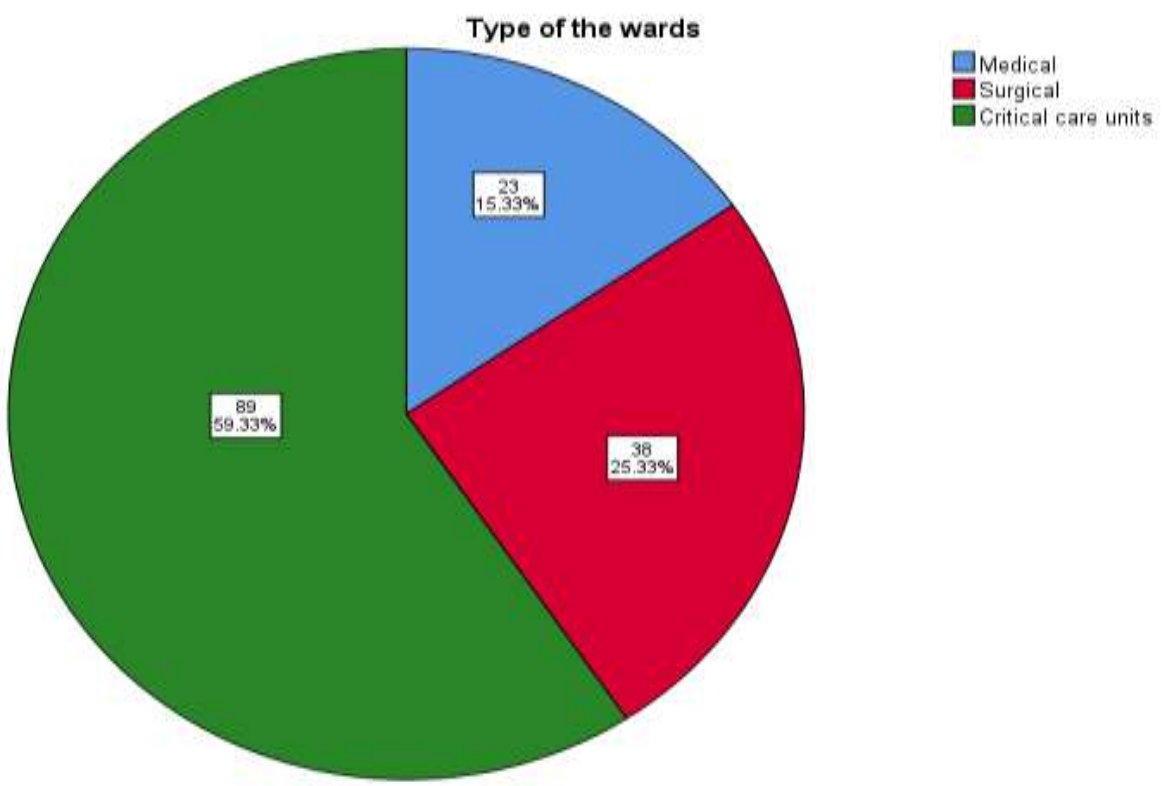

Figure 3

Figure 4 shows that the length of stay (days) in hospital of the participants was found as $22(14.3 \%)$ were stayed in hospital for 1-10 days, 43 (28.3\%) were stay for 11-20 days, majority 53 (35.2\%) were stay 21-30 days and 32 (21.2\%) stay for 31 or more than 31 days. 

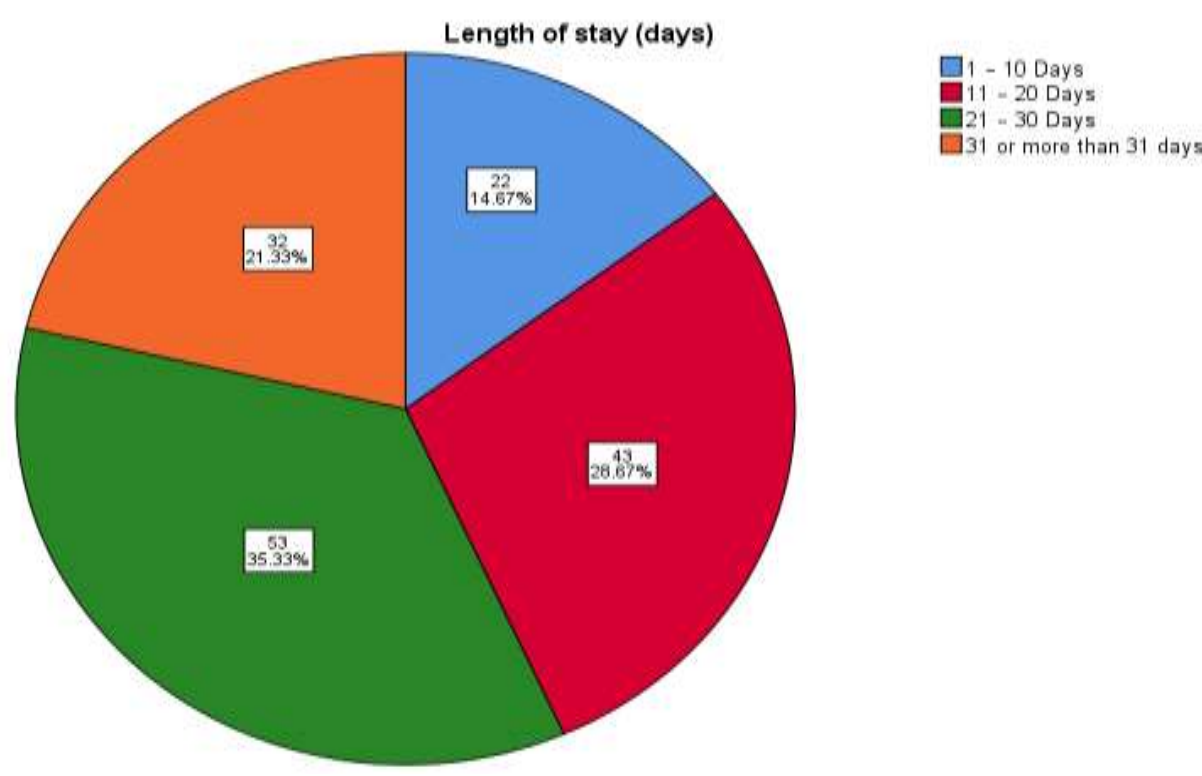

Figure 4

Figure 5 shows that only 37 (24.7\%) participants have not previously hospitalised and majority 113 (75,3\%) previously hospitalised.

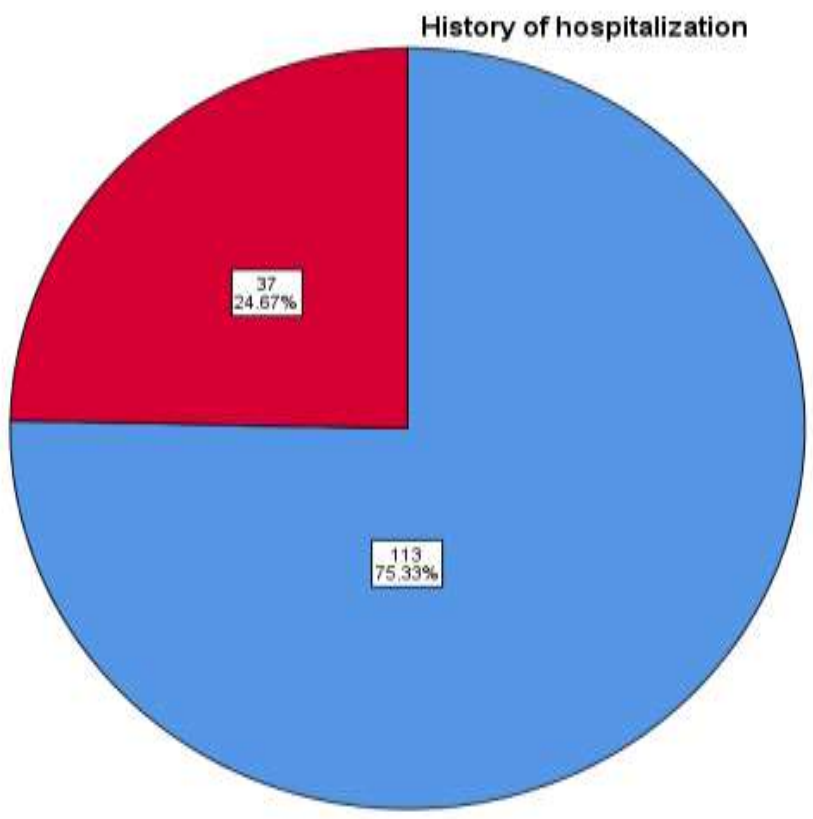

Previously hospitalised

Not Previously hospitalised

Figure 5

Figure 6 shows that the assessment regarding history of pressure ulcer and results revealed that majority 78 (52\%) have not previous history of ulcer and $72(48 \%)$ have previous history of ulcer 


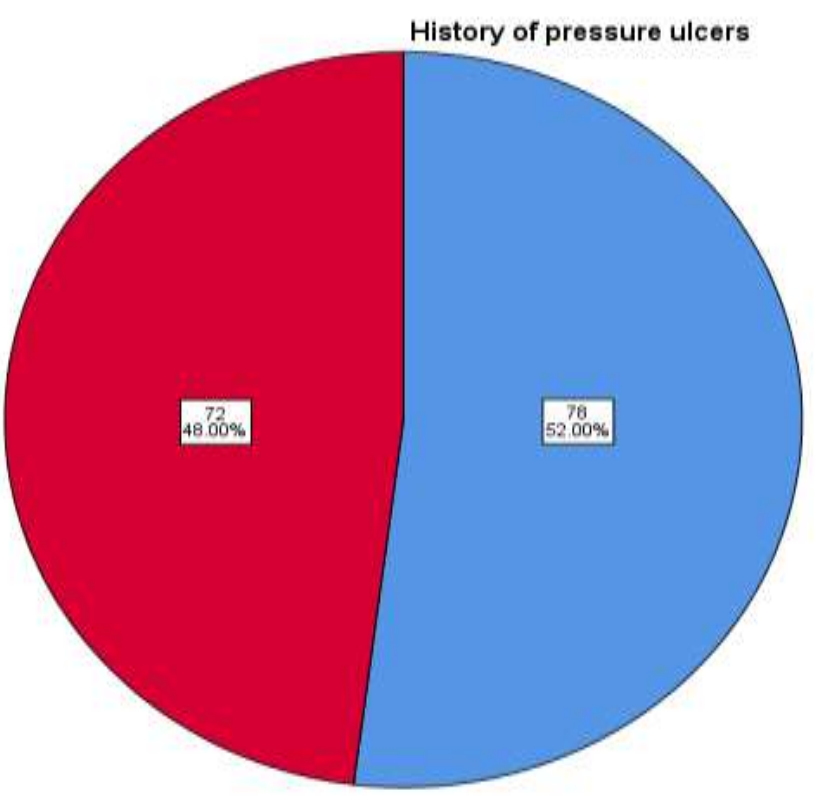

No previous ulcers History

History of previous ulcers

Figure 6

Figure 7 shows that the frequency of observation regarding presence of pressure ulcers, and results revealed that 92 $(61.3 \%)$ have pressure ulcer at the time of study and $58(38.7 \%)$ have not ulcer at the time of study.

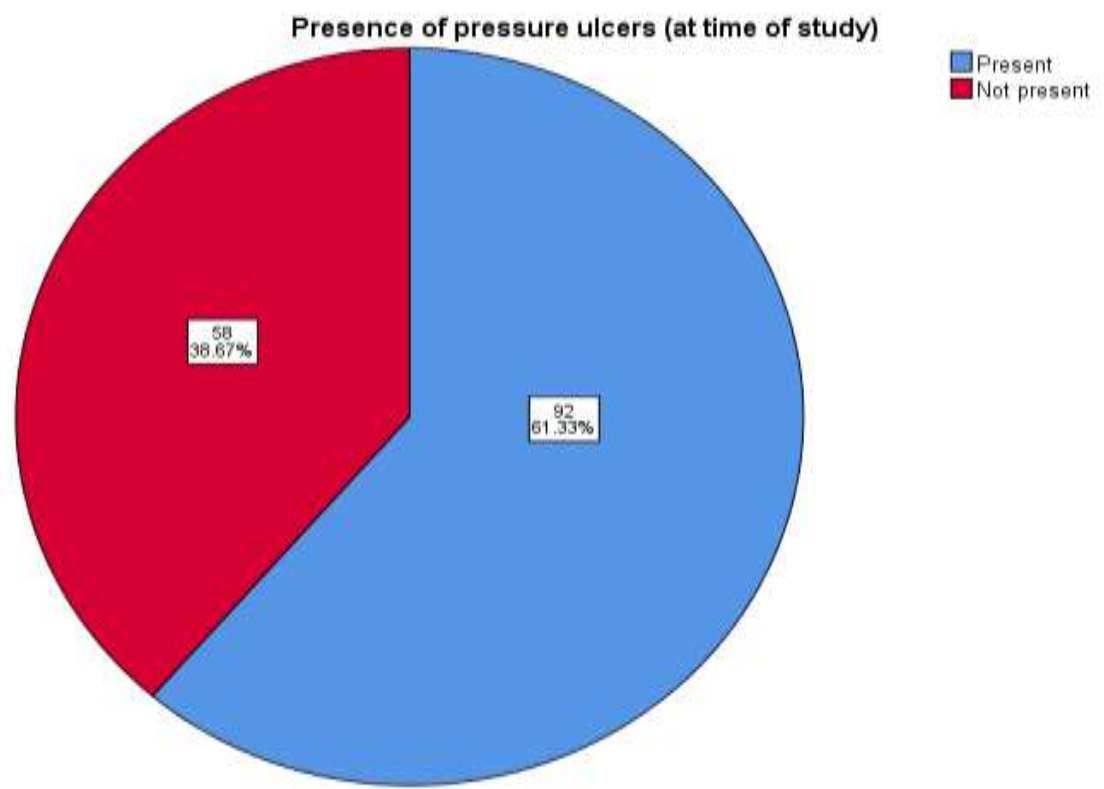

Figure 7

Table 2 shows the mean, median, mode and standard deviation of demographic variable the highest mean 2.97 for History of hospitalization, then 2.63 for Length of stay (days) and 2.44 for Type of the wards, 1.48 and 1.47 for history of pressure ulcer and gender respectively and the History of hospitalization lowest mean was 1.25. The Std. Deviation is $(.501,1.003, .963, .746, .433, .501, .489)$ were respectively for, gender, age, History of hospitalization, Qualification, Type of the wards, Length of stay (days), History of pressure ulcers and Presence of pressure ulcers (at time of study). Highest median value is 3.00 and highest mode value is 4 . 
Demographics data statistics

\begin{tabular}{|l|c|c|c|c|c|}
\hline \multicolumn{1}{|c|}{ Variable } & N & Mean & Median & Mode & $\begin{array}{c}\text { Std. } \\
\text { Deviation }\end{array}$ \\
\hline Gender & 150 & 1.47 & 1.00 & 1 & .501 \\
\hline Age & 150 & 2.97 & 3.00 & 4 & 1.003 \\
\hline History of hospitalization & 150 & 1.25 & 1.00 & 1 & .963 \\
\hline Type of the wards & 150 & 2.44 & 3.00 & 3 & .746 \\
\hline Length of stay (days) & 150 & 2.63 & 3.00 & 3 & .433 \\
\hline History of pressure ulcers & 150 & 1.48 & 1.00 & 1 & .501 \\
\hline $\begin{array}{l}\text { Presence of pressure ulcers (at } \\
\text { time of study) }\end{array}$ & 150 & 1.39 & 1.00 & 1 & .489 \\
\hline
\end{tabular}

Table 2

Section B, consist of check list regarding prevention of decubitus ulcers consisting 29 items.

Table 4 shows the frequency percentage of 27 items of checklist regarding prevention of decubitus ulcers and results revealed that mostly above $60 \%$ nurses have good practices and follow the standard guideline for prevention of decubitus ulcers of admitted patient in different ward such as surgical, medical and critical care unite. Further the observation revealed that the participant relates to different level of age group and the observation regarding first item of checklist results revealed that the $76(50.1 \%)$ were observed as Risk assessment undertaken on admission, 53 (35.4\%) were not observed and only $21(14.6 \%)$ assess as not applicable while giving care to the patients regarding prevention of pressure ulcer. Item two is "Recording of risk assessment scores" and results revealed that the 66 (44.1\%) were observed, $61(40.9 \%)$ were observed and only $23(15 \%)$ observed as not applicable. Item three is "Systematic inspection of skin" and results revealed that the $93(62 \%)$ were observed, $61(40.9 \%)$ were not observed and only $18(12 \%)$ were observed as not applicable. The observation regarding fourth item of checklist and results revealed that the $92(61 \%)$ were observed as recording of results of skin inspection, $48(32.3 \%)$ were not observed and only $10(6.7 \%)$ assess as not applicable while giving care to the patients regarding prevention of pressure ulcer. Item five is "Cleaning of the skin" and results revealed that the $88(58 \%)$ were observed, $42(28.4 \%)$ were observed and only $20(13.6 \%)$ observed as not applicable while give care to the patients. Item six is "Minimum force and friction during cleaning" and results revealed that the $81(54 \%)$ were observed, $63(42 \%)$ were not observed and only $6(4 \%)$ were observed as not applicable regarding decubitus ulcer prevention. The observation regarding seventh item of checklist and results revealed that the $93(62 \%)$ were observed as application of moisturizing agents, $44(29.4 \%)$ were not observed and only $13(8.7 \%)$ assess as not applicable while giving care to the patients regarding prevention of pressure ulcer. Item eight is "Minimum exposure to moisture" and results revealed that the $92(61 \%)$ were observed, $38(25.3 \%)$ were observed and only $20(13.6 \%)$ observed as not applicable while give care to the patients. Item nine is "Use of barrier against moisture" and results revealed that the 98 (65.3\%) were observed, 35 (23.3\%) were not observed and only 17 (11.3\%) were observed as not applicable regarding decubitus ulcer prevention. The observation regarding item ten of checklist and results revealed that the $91(60.3 \%)$ were observed as skin protection during transfers, 55 (26.7\%) were not observed and only $4(2.6 \%)$ assess as not applicable while giving care to the patients regarding prevention of pressure ulcer. Item eleven is "Changing positions and turning" and results revealed that the $94(62.3 \%)$ were observed, $41(27.7 \%)$ were observed and only $15(10 \%)$ observed as not applicable while give care to the patients. Item twelve is "Recording the nursing interventions and its results" and results revealed that the 87 (58\%) were observed, $52(34.7 \%)$ were not observed and only $11(7.3 \%)$ were observed as not applicable regarding decubitus ulcer prevention. The observation regarding item thirteen of checklist and results revealed that the 105 (70\%) were observed as repositioning, $26(17.3 \%)$ were not observed and only $19(12.3 \%)$ assess as not applicable while giving care to the patients regarding prevention of pressure ulcer. Item fourteen is "Use of a chart for changing position and turning:" and results revealed that the $95(63 \%)$ were observed, $48(32.3 \%)$ were observed and only 7 (4.7\%) observed as not applicable while give care to the patients. Item fifteen is "Using devices to prevent contact." and results revealed that the $100(66 \%)$ were observed, $39(26.7 \%)$ were not observed and only $11(7.3 \%)$ were observed as not applicable regarding decubitus ulcer prevention. The observation regarding item sixteen of checklist and results revealed that the $116(77.3 \%)$ were observed as heels lifted to decrease pressure, $29(19.3 \%)$ were not observed and only $5(3.3 \%)$ assess as not applicable while giving care to the patients regarding prevention of pressure ulcer. Item seventeen is "Minimizing the period in which the head of the bed tilted more than 30 degrees" and results revealed that the $101(67.3 \%)$ were observed, 35 (23.3\%) were observed and only $14(9.3 \%)$ observed as not applicable while give care to the patients. Item eighteen is "Patient mobilized (where possible) Use of pressure relieving mattress" 
and results revealed that the 87 (58\%) were observed, 40 (26.7\%) were not observed and only $23(15.3 \%)$ were observed as not applicable regarding decubitus ulcer prevention. The observation regarding item nineteen of checklist and results revealed that the $96(64 \%)$ were observed as taught how to reposition themselves when sitting on the chair, $44(29.3 \%)$ were not observed and only $10(6.7 \%)$ assess as not applicable while giving care to the patients regarding prevention of pressure ulcer. The observation regarding item twenty of checklist and results revealed that the 106 (70.6\%) were observed as when sitting on the chair position changed every hour or transferred to bed, 27 (18\%) were not observed and only $17(11.4 \%)$ assess as not applicable while giving care to the patients regarding prevention of pressure ulcer. Item twenty-one is "Use of pressure relieving devices on chairs" and results revealed that the 96 (64\%) were observed, $39(26.7 \%)$ were not observed and only $15(10 \%)$ were observed as not applicable regarding decubitus ulcer prevention. Item twenty-two is "Nutritional assessment" and results revealed that the $102(68 \%)$ were observed, $36(24 \%)$ were not observed and only $12(8 \%)$ were observed as not applicable regarding decubitus ulcer prevention. Item twenty-three is "Assisted with eating and drinking" and results revealed that the 77 (51.3\%) were observed, 41 $(27 \%)$ were not observed and only $32(21 \%)$ were observed as not applicable regarding decubitus ulcer prevention. Item twenty-four is "Recording of nutritional assessment" and results revealed that the $86(57.3 \%)$ were observed, 44 (29.3\%) were not observed and only $20(13.3 \%)$ were observed as not applicable regarding decubitus ulcer prevention. Item twenty-five is "Patients given information on the prevention of pressure sores" and results revealed that the 52 (34\%) were observed, 74 (49.3\%) were not observed and only 24 (16.7\%) were observed as not applicable regarding decubitus ulcer prevention. The observation regarding item twenty-six of checklist and results revealed that the 75 (50\%) were observed as relatives given information on the prevention of pressure sores, $53(35.3 \%)$ were not observed and only $22(14.6 \%)$ assess as not applicable while giving care to the patients regarding prevention of pressure ulcer. The observation regarding item twenty-seven of checklist and results revealed that the $52(34.6 \%)$ were observed as Support staff given information on the prevention of pressure sores, 74 (49.4\%) were not observed and only 24 (16\%) assess as not applicable while giving care to the patients regarding prevention of pressure ulcer.

\begin{tabular}{|l|c|c|c|c|c|c|}
\hline \multicolumn{1}{|c|}{ Checklist Items } & $\begin{array}{c}\text { Observe } \\
\mathbf{d} \\
\text { Frequen } \\
\text { cy }\end{array}$ & $\begin{array}{c}\text { Valid } \\
\text { Percent }\end{array}$ & $\begin{array}{c}\text { Not } \\
\text { observed } \\
\text { Frequen } \\
\text { cy }\end{array}$ & $\begin{array}{c}\text { Valid } \\
\text { Percent }\end{array}$ & $\begin{array}{c}\text { Not } \\
\text { applicab } \\
\text { le } \\
\text { Frequen } \\
\text { cy }\end{array}$ & $\begin{array}{c}\text { Valid } \\
\text { Percent }\end{array}$ \\
\hline Risk assessment undertaken.... & 76 & $50.1 \%$ & 53 & $35.4 \%$ & 21 & $14.6 \%$ \\
\hline Recording of risk assessment.... & 66 & $44.1 \%$ & 61 & $40.9 \%$ & 23 & $15 \%$ \\
\hline Systematic inspection of skin: & 93 & $62 \%$ & 39 & $26 \%$ & 18 & $12 \%$ \\
\hline Recording of results of skin...... & 92 & $61 \%$ & 48 & $32.3 \%$ & 10 & $6.7 \%$ \\
\hline Cleaning of the skin........ & 88 & $58 \%$ & 42 & $28.4 \%$ & 20 & $13.6 \%$ \\
\hline Minimum force and friction..... & 81 & $54 \%$ & 63 & $42 \%$ & 6 & $4 \%$ \\
\hline Application of moisturizing...... & 93 & $62 \%$ & 44 & $29.3 \%$ & 13 & $8.7 \%$ \\
\hline Minimum exposure to moisture: & 92 & $61 \%$ & 38 & $25.3 \%$ & 20 & $13.6 \%$ \\
\hline Use of barrier against moisture: & 98 & $65.3 \%$ & 35 & $23.3 \%$ & 17 & $11.3 \%$ \\
\hline Skin protection during transfers: & 91 & $60.7 \%$ & 55 & $36.7 \%$ & 4 & $2.6 \%$ \\
\hline Changing positions and turning: & 94 & $62.3 \%$ & 41 & $27.7 \%$ & 15 & $10 \%$ \\
\hline Recording the nursing......... & 87 & $58 \%$ & 52 & $34.7 \%$ & 11 & $7.3 \%$ \\
\hline Repositioning: & 105 & $70 \%$ & 26 & $17.3 \%$ & 19 & $12.3 \%$ \\
\hline Use of a chart for changing...... & 95 & $63 \%$ & 48 & $32.3 \%$ & 7 & $4.7 \%$ \\
\hline Using devices to prevent contact. & 100 & $66 \%$ & 39 & $26 \%$ & 11 & $7.3 \%$ \\
\hline Heels lifted to decrease pressure: & 116 & $77.3 \%$ & 29 & $19.3 \%$ & 5 & $3.3 \%$ \\
\hline Minimizing the period in which... & 101 & $67.3 \%$ & 35 & $23.3 \%$ & 14 & $9.3 \%$ \\
\hline Patient mobilized........... & 87 & $58 \%$ & 40 & $26.7 \%$ & 23 & $15.3 \%$ \\
\hline Taught how to reposition....... & 96 & $64 \%$ & 44 & $29.3 \%$ & 10 & $6.7 \%$ \\
\hline When sitting on the chair position & 106 & $70.6 \%$ & 27 & $18 \%$ & 17 & $11.4 \%$ \\
\hline Use of pressure relieving devices. & 96 & $64 \%$ & 39 & $26 \%$ & 15 & $10 \%$ \\
\hline Nutritional assessment: & 102 & $68 \%$ & 36 & $24 \%$ & 12 & $8 \%$ \\
\hline Assisted with eating and drinking: & 77 & $51.3 \%$ & 41 & $27 \%$ & 32 & $21 \%$ \\
\hline Recording of nutritional...... & 86 & $57.3 \%$ & 44 & $29.3 \%$ & 20 & $13.3 \%$ \\
\hline
\end{tabular}




\begin{tabular}{|l|c|c|c|c|c|c|}
\hline Patients given information on the. & 52 & $34 \%$ & 74 & $49.3 \%$ & 24 & $16.7 \%$ \\
\hline Relatives given information.... & 75 & $50 \%$ & 53 & $35.3 \%$ & 22 & $14.6 \%$ \\
\hline Support staff given information... & 52 & $34.6 \%$ & 74 & $49.4 \%$ & 24 & $16 \%$ \\
\hline
\end{tabular}

Table 3

Table 4 shows that the statistics (mean, median, mode and standard deviation) of 27 items of checklist regarding practices regarding prevention of decubitus ulcer and results revealed that the highest mean value is 1.71 of item two which is "Recording of risk assessment scores" and other two items and comparatively lowest mean value is 1.45 for item four which is "Recording of results of skin inspection" and two items. The mean value for others item is between 1.45-1.71 respectively. Median and mode value of most of items is 1 and highest is 2 . Standard deviation value .720 is highest and comparatively .576 is low.

\begin{tabular}{|c|c|c|c|c|c|}
\hline Variable & $\mathbf{N}$ & Mean & Median & Mode & $\begin{array}{c}\text { Std. } \\
\text { Deviation }\end{array}$ \\
\hline Risk assessment undertaken on admission: & 150 & 1.63 & 1 & 1 & .718 \\
\hline Recording of risk assessment scores: & 150 & 1.71 & 2.00 & 1 & .717 \\
\hline Systematic inspection of skin: & 150 & 1.50 & 1 & 1 & .702 \\
\hline Recording of results of skin inspection: & 150 & 1.45 & 1 & 1 & .619 \\
\hline Cleaning of the skin: & 150 & 1.55 & 1 & 1 & .720 \\
\hline Minimum force and friction during cleaning: & 150 & 1.50 & 1 & 1 & .576 \\
\hline Application of moisturizing agents: & 150 & 1.47 & 1 & 1 & .652 \\
\hline Minimum exposure to moisture: & 150 & 1.52 & 1 & 1 & .721 \\
\hline Use of barrier against moisture: & 150 & 1.46 & 1 & 1 & .692 \\
\hline Skin protection during transfers: & 150 & 1.63 & 1 & 1 & .717 \\
\hline Changing positions and turning: & 150 & 1.71 & 1 & 1 & .718 \\
\hline Recording the nursing interventions and its... & 150 & 1.45 & 1 & 1 & .702 \\
\hline Repositioning: & 150 & 1.50 & 1 & 1 & .619 \\
\hline Use of a chart for changing position........ & 150 & 1.55 & 1 & 1 & .720 \\
\hline Using devices to prevent contact between bony & 150 & 1.50 & 1 & 1 & .576 \\
\hline Heels lifted to decrease pressure: & 150 & 1.47 & 1 & 1 & .652 \\
\hline Minimizing the period in which the head of the & 150 & 1.52 & 1 & 1 & .721 \\
\hline Patient mobilized (where possible) Use of..... & 150 & 1.46 & 1 & 1 & .692 \\
\hline Taught how to reposition themselves when..... & 150 & 1.63 & 1 & 1 & .718 \\
\hline When sitting on the chair position changed..... & 150 & 1.71 & 1 & 1 & .717 \\
\hline Use of pressure relieving devices on chairs: & 150 & 1.50 & 1 & 1 & .702 \\
\hline Nutritional assessment: & 150 & 1.45 & 1 & 1 & .619 \\
\hline Assisted with eating and drinking: & 150 & 1.55 & 1 & 1 & .720 \\
\hline Recording of nutritional assessment: & 150 & 1.50 & 1 & 1 & .576 \\
\hline Patients given information on the prevention of & 150 & 1.47 & 1 & 1 & .612 \\
\hline Relatives given information on the prevention & 150 & 1.52 & 1.50 & 1 & .719 \\
\hline Support staff given information on the & 150 & 1.46 & 2.00 & 2 & .692 \\
\hline
\end{tabular}

Table 4

Figure 8 shows that the observation regarding first item of checklist results revealed that the $76(50.1 \%)$ were observed as Risk assessment undertaken on admission, 53 (35.4\%) were not observed and only 21 assess as not applicable while giving care to the patients regarding prevention of pressure ulcer. 


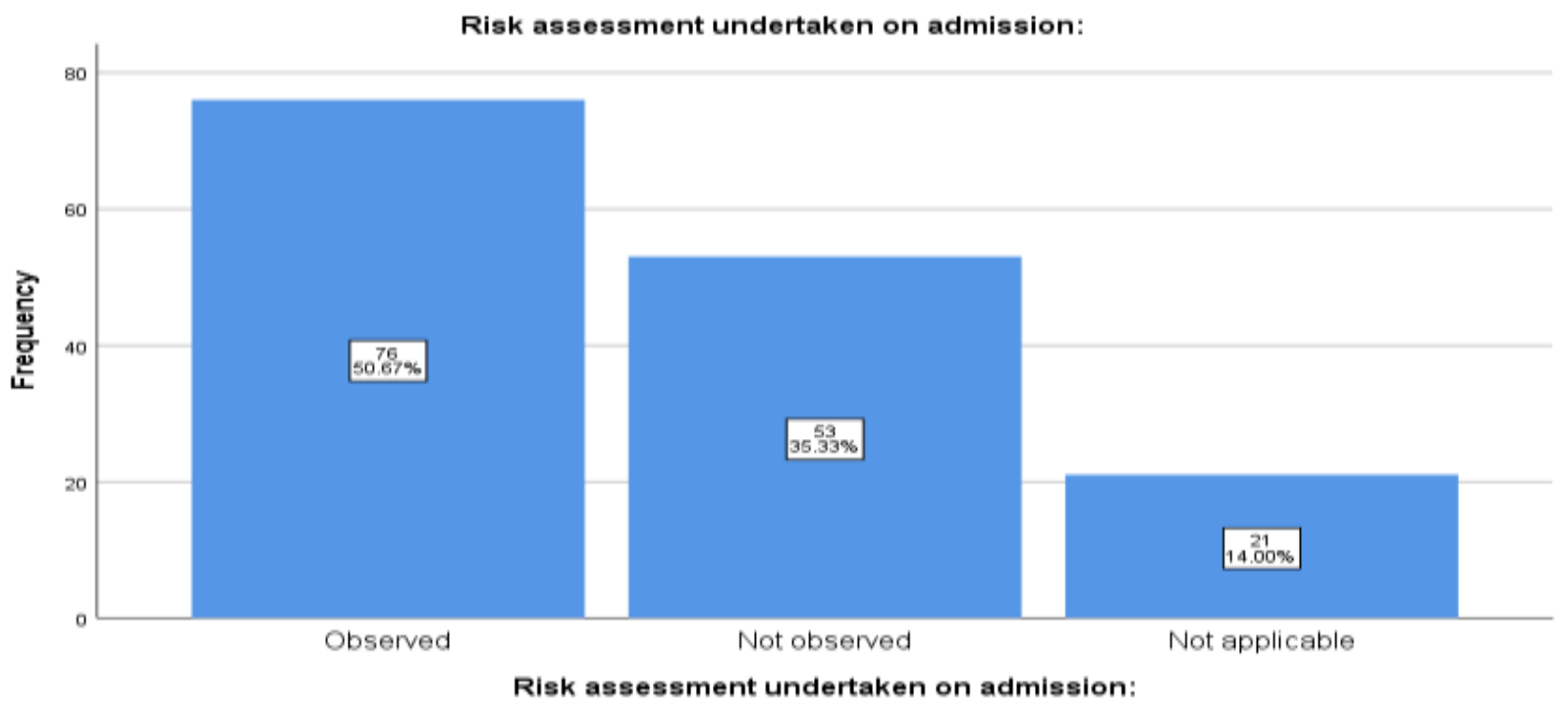

Figure 8

Figure 9 shows that the observation regarding item two is "Recording of risk assessment scores" and results revealed that the $66(44.1 \%)$ were observed, $61(40.9 \%)$ were observed and only $23(15 \%)$ observed as not applicable.

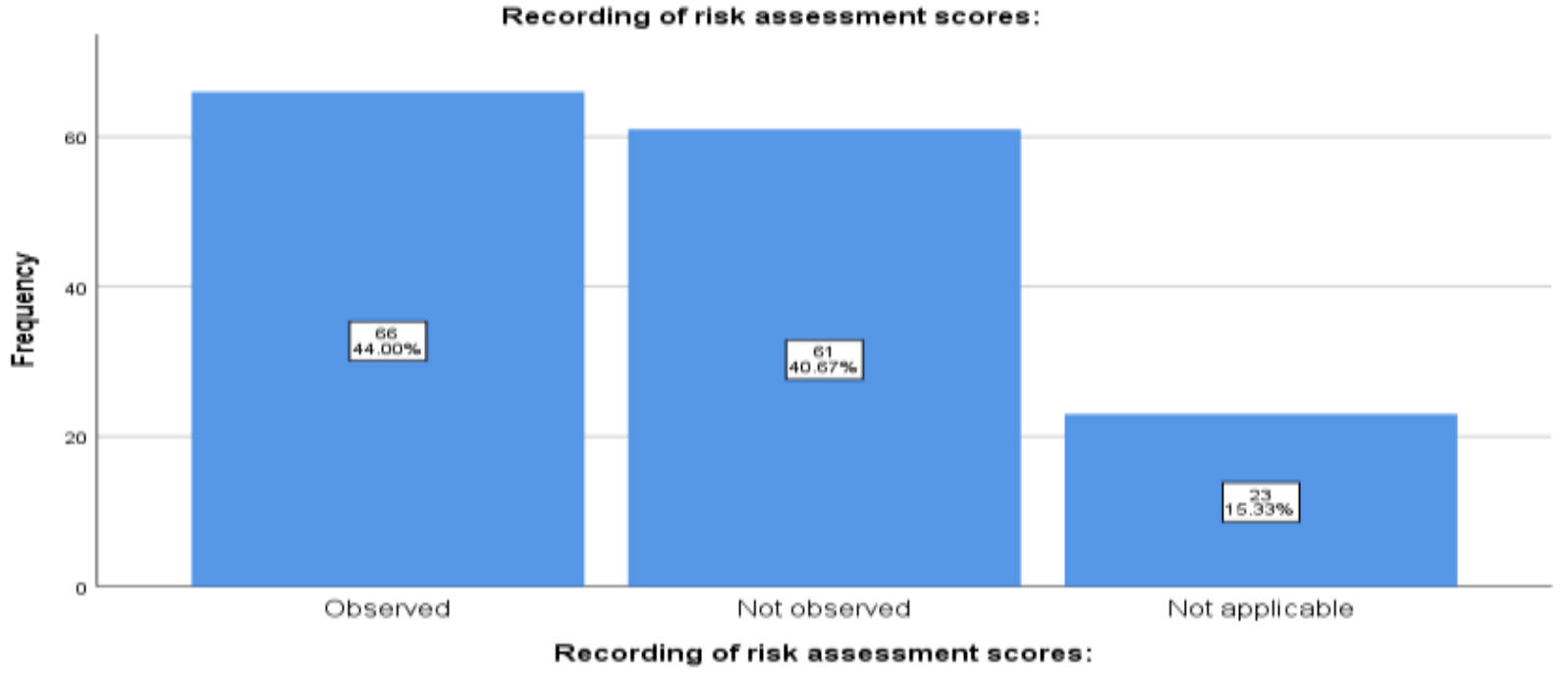

Figure 9

Figure 10 shows that the observation regarding item three is "Systematic inspection of skin" and results revealed that the $93(62 \%)$ were observed, 61 (40.9\%) were not observed and only $18(12 \%)$ were observed as not applicable. 


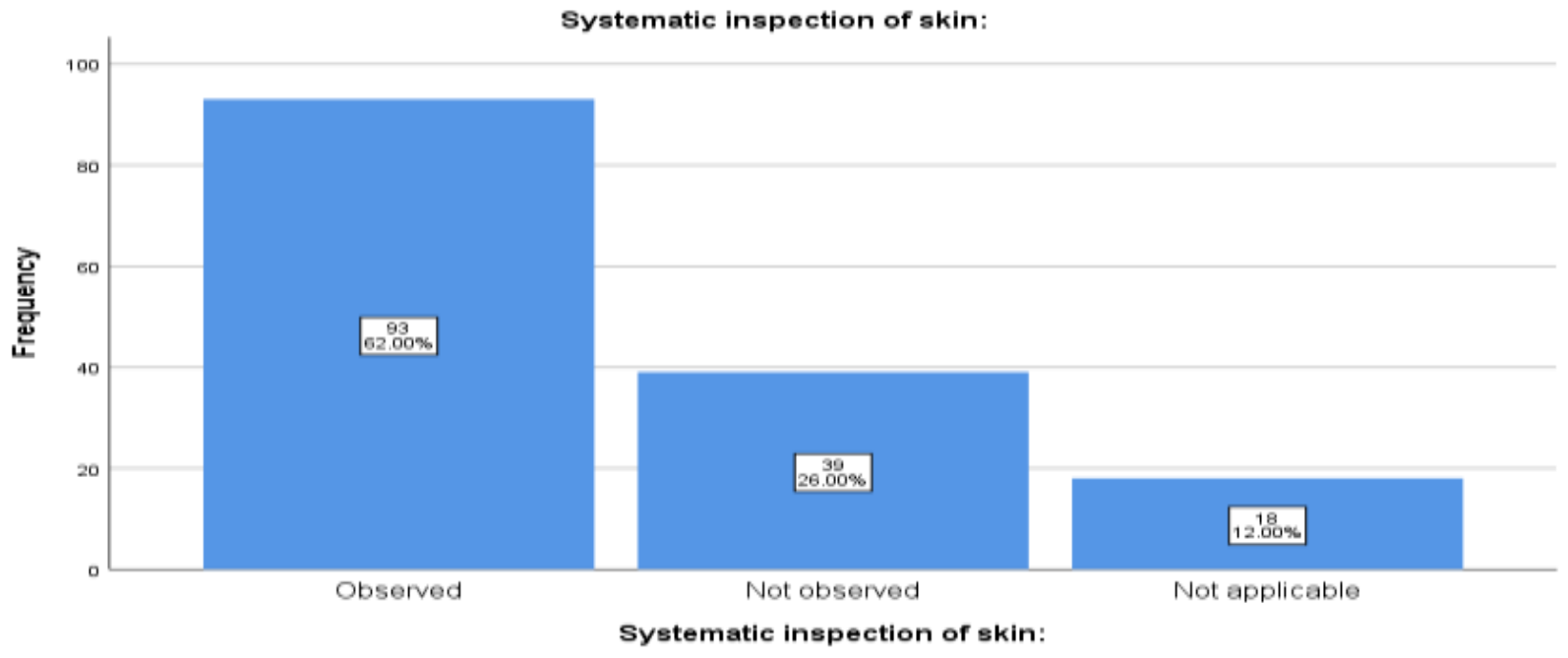

Figure 10

Figure 11 shows that the observation regarding fourth item of checklist and results revealed that the $92(61 \%)$ were observed as recording of results of skin inspection, 48 (32.3\%) were not observed and only $10(6.7 \%)$ assess as not applicable while giving care to the patients regarding prevention of pressure ulcer.

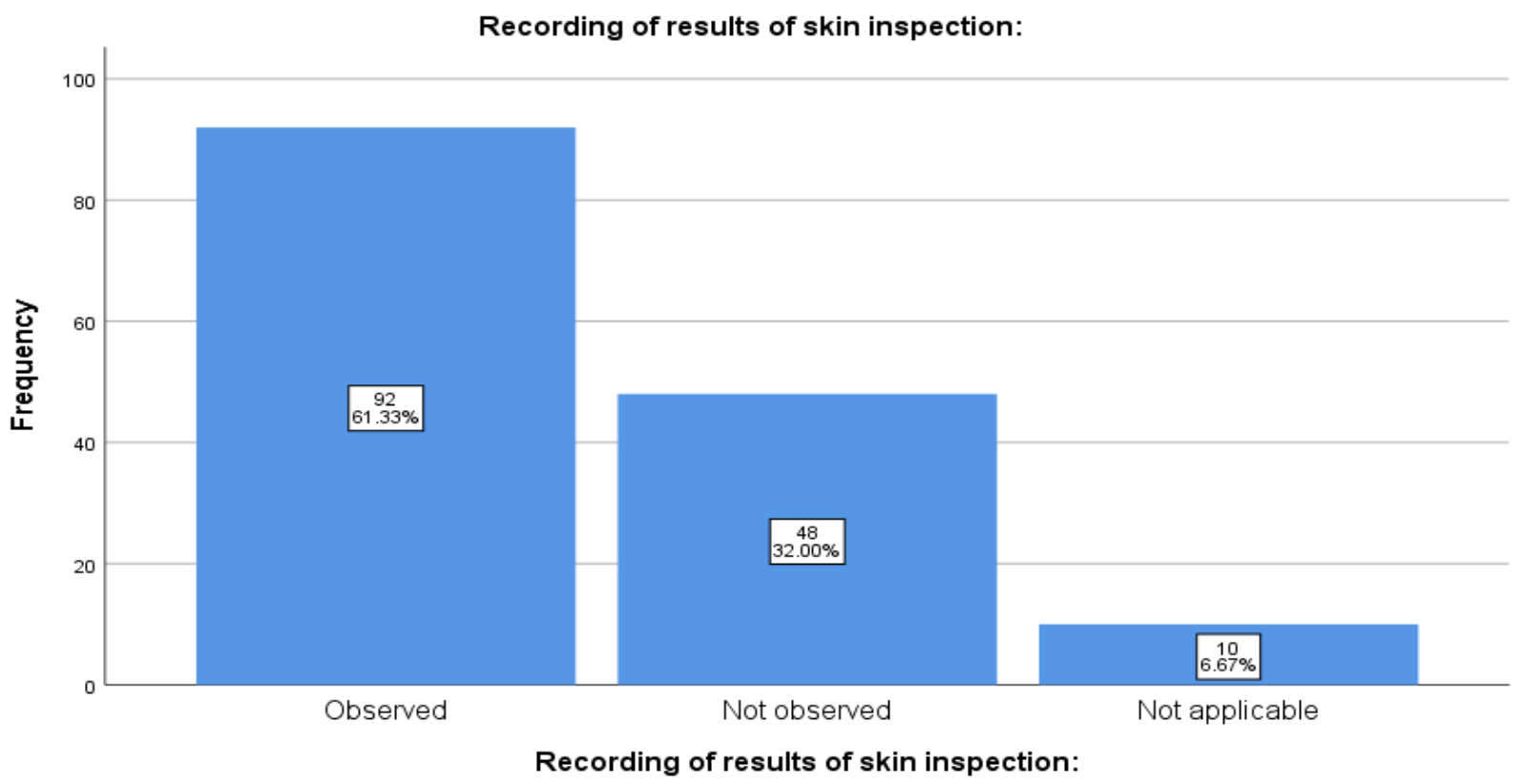

Figure 11

Figure 12 shows that the results of Item five which is "Cleaning of the skin" and results revealed that the 88 (58\%) were observed, $42(28.4 \%)$ were observed and only $20(13.6 \%)$ observed as not applicable while give care to the patients. 


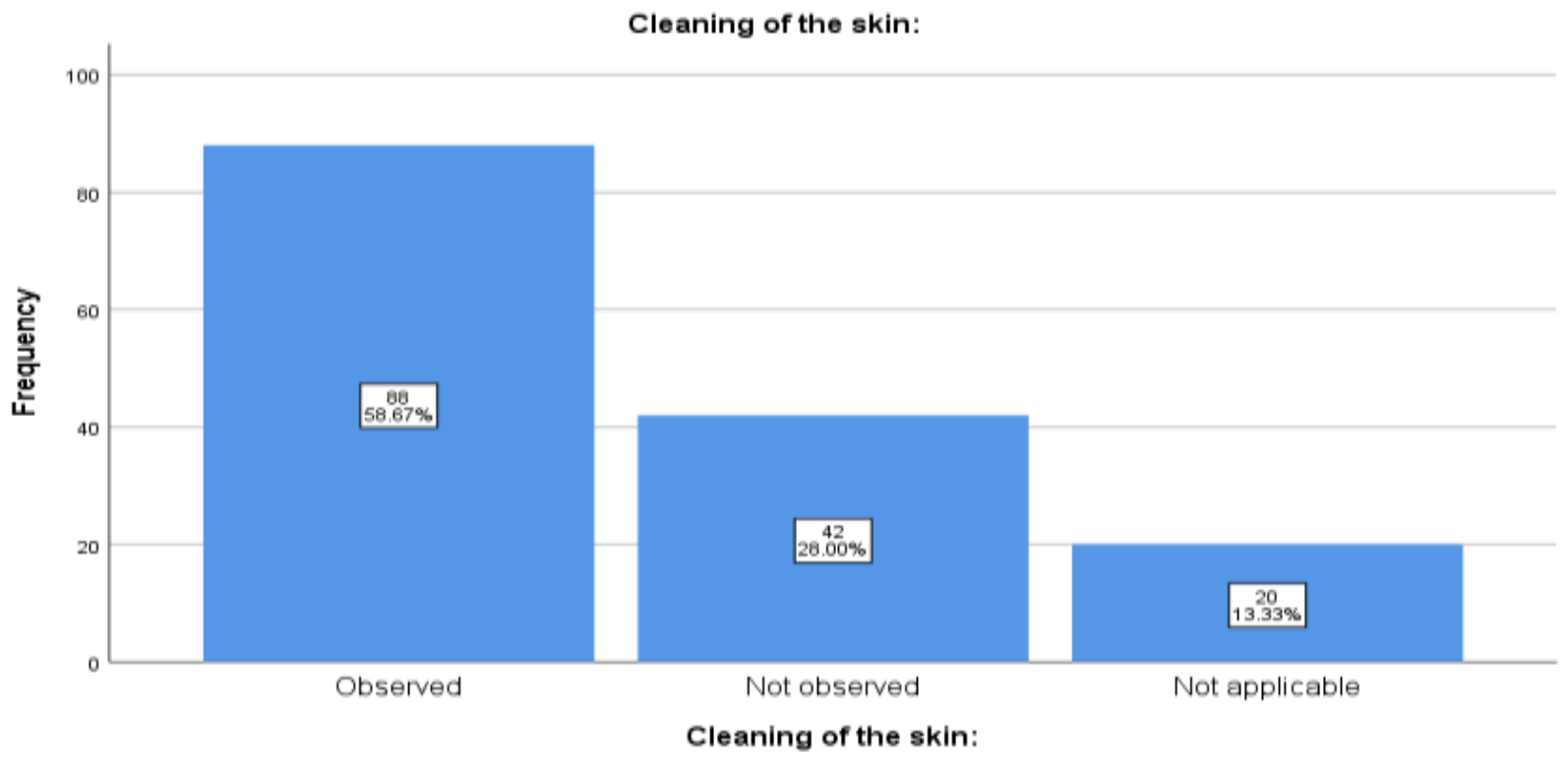

Figure 12

Figure 13 shows that the results of Item six which is "Minimum force and friction during cleaning" and results revealed that the $81(54 \%)$ were observed, $63(42 \%)$ were not observed and only $6(4 \%)$ were observed as not applicable regarding decubitus ulcer prevention.

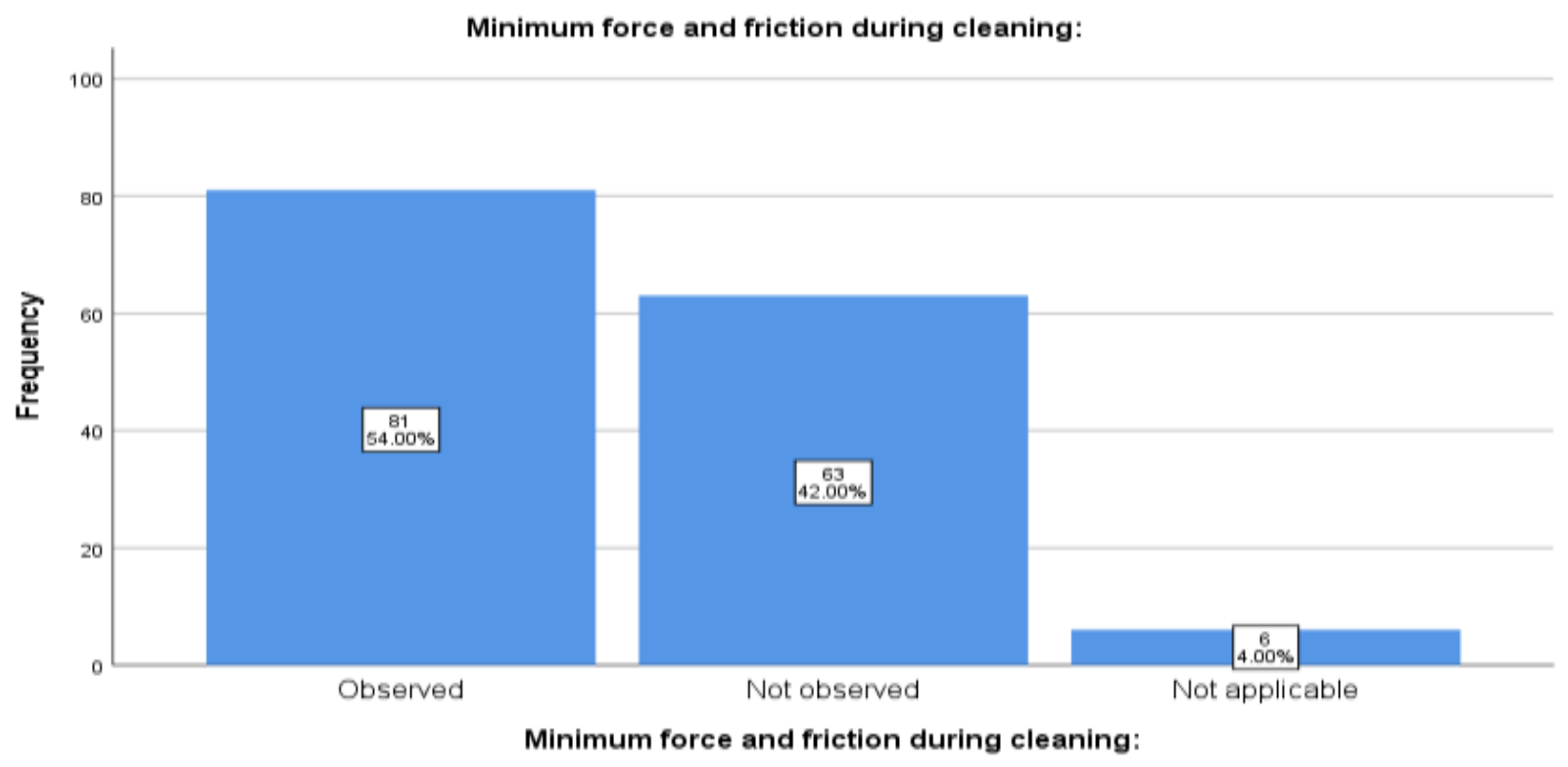

Figure 13

Figure 14 shows that the observation regarding seventh item of checklist and results revealed that the 93 (62\%) were observed as application of moisturizing agents, $44(29.4 \%)$ were not observed and only $13(8.7 \%)$ assess as not applicable while giving care to the patients regarding prevention of pressure ulcer. 


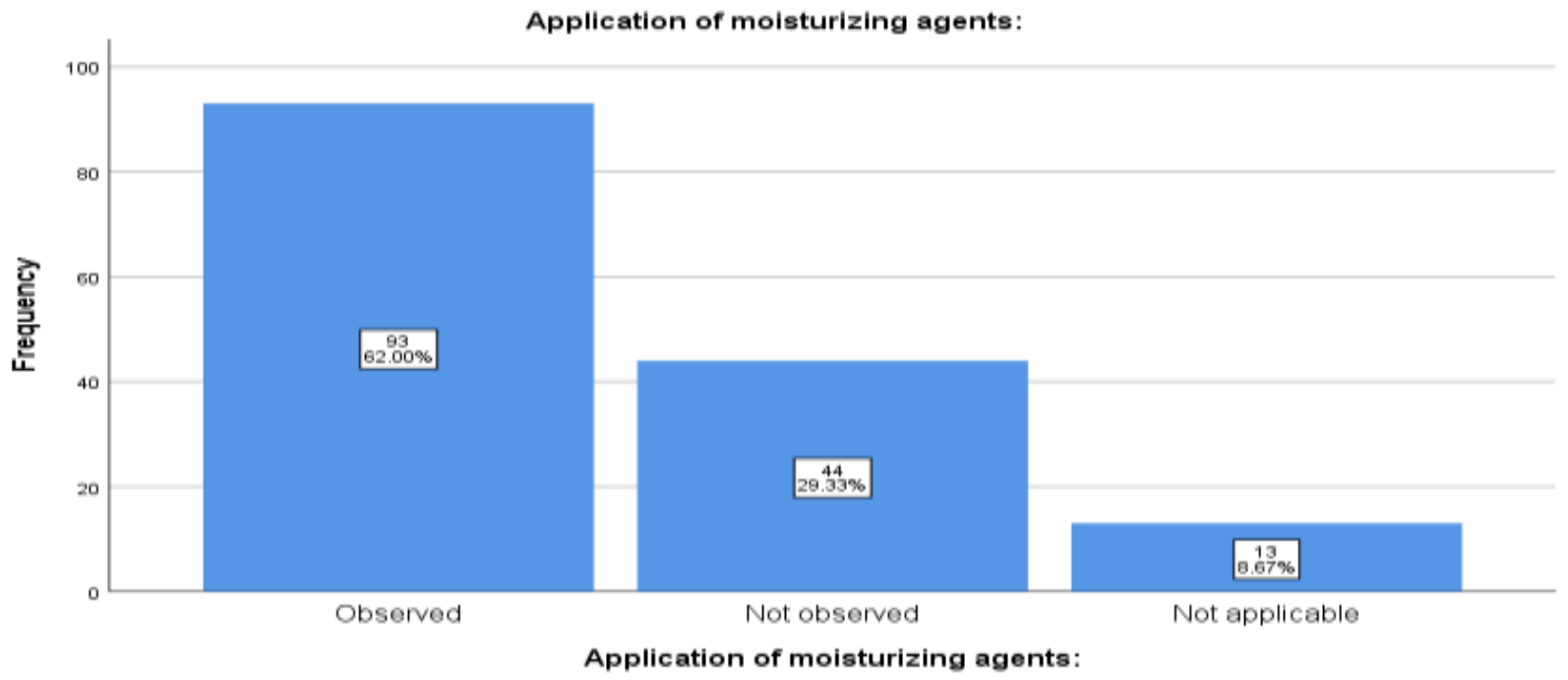

Figure 14

Figure 15 shows that the observation regarding Item eight which is "Minimum exposure to moisture" and results revealed that the $92(61 \%)$ were observed, 38 (25.3\%) were observed and only $20(13.6 \%)$ observed as not applicable while give care to the patients.

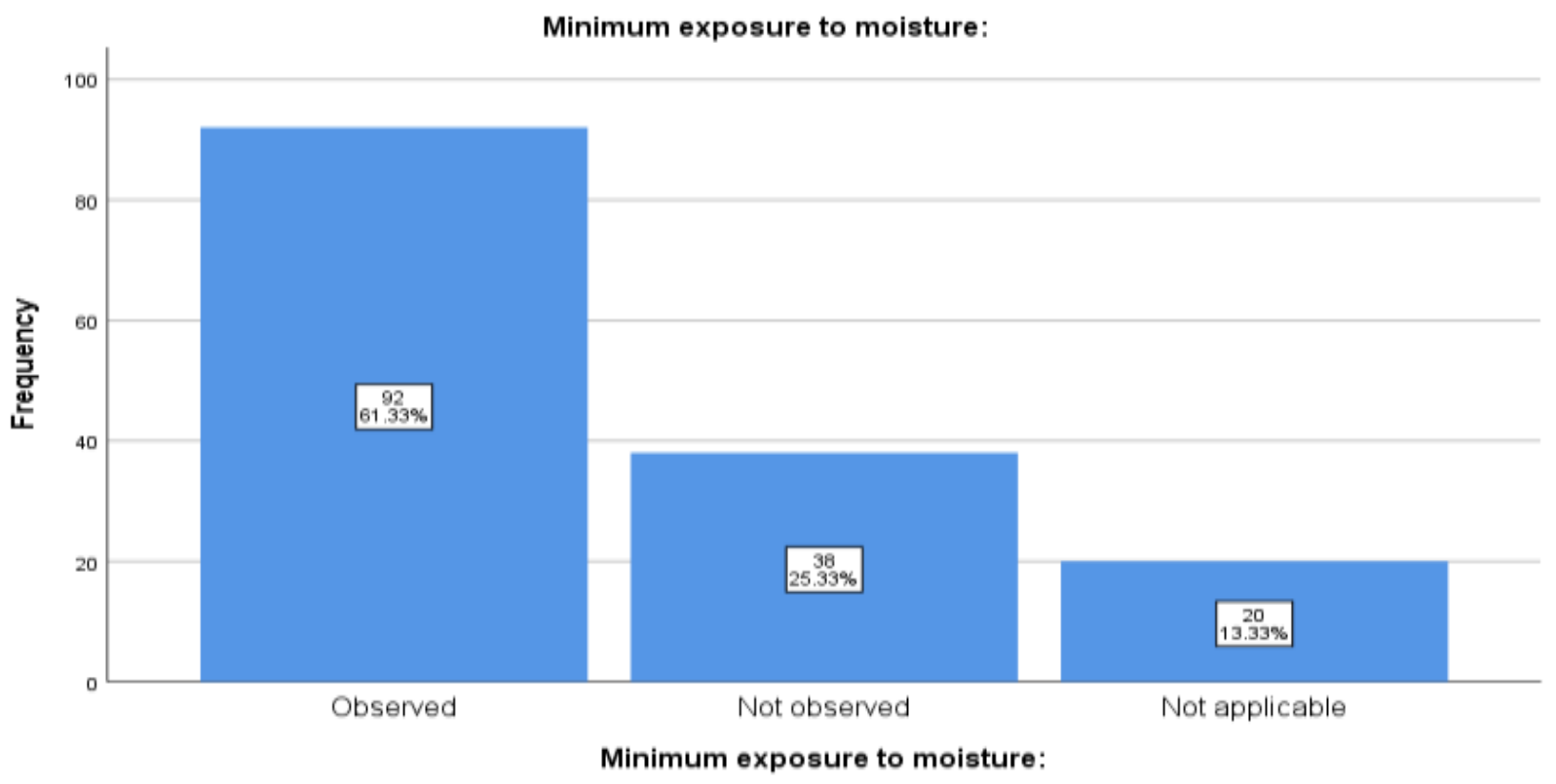

Figure 15

Figure 16 shows that the results regarding item nine which is "Use of barrier against moisture" and results revealed that the 98 (65.3\%) were observed, $35(23.3 \%)$ were not observed and only 17 (11.3\%) were observed as not applicable regarding decubitus ulcer prevention. 


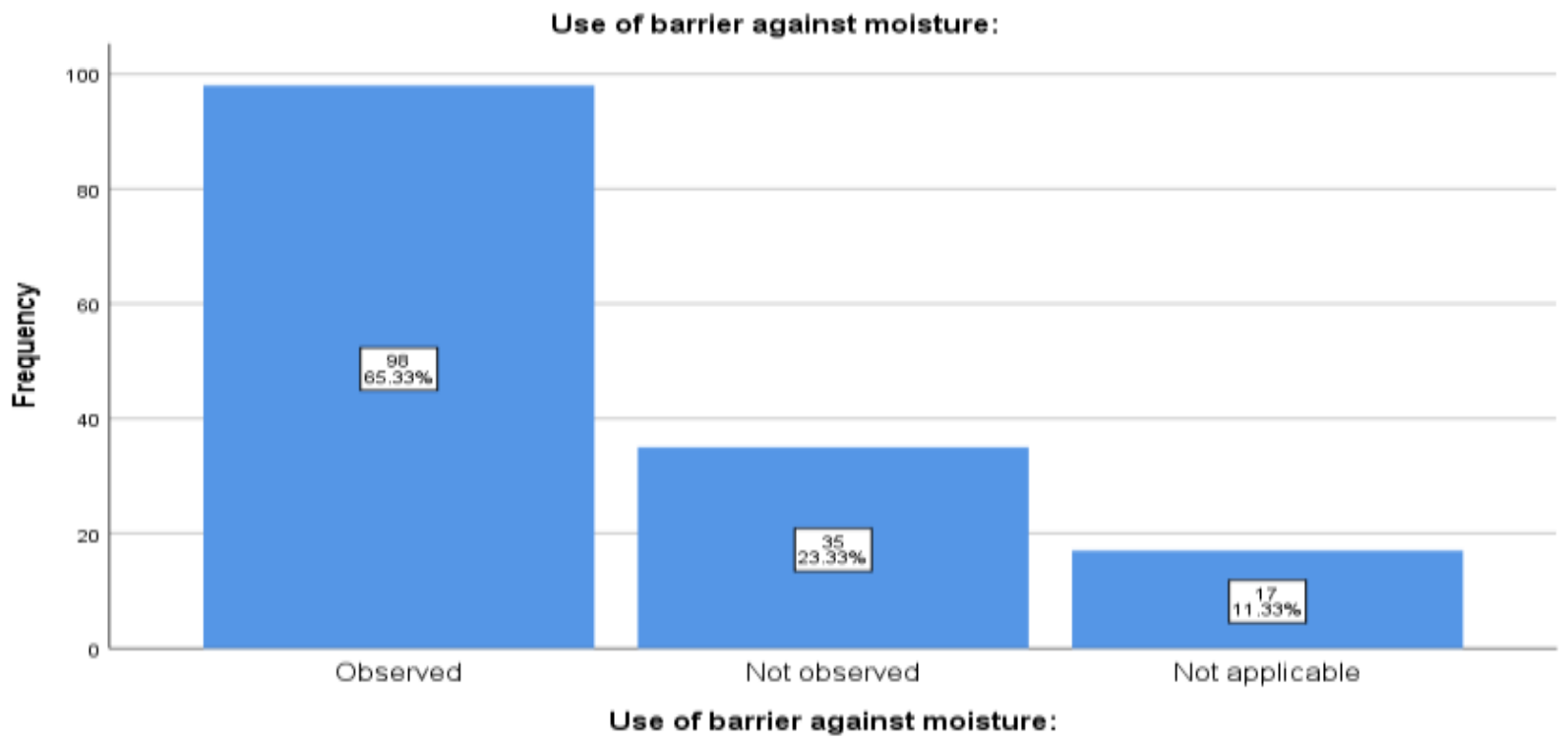

Figure 16

Figure 17 shows that the observation regarding item ten of checklist and results revealed that the $91(60.3 \%)$ were observed as skin protection during transfers, $55(26.7 \%)$ were not observed and only $4(2.6 \%)$ assess as not applicable while giving care to the patients regarding prevention of pressure ulcer.

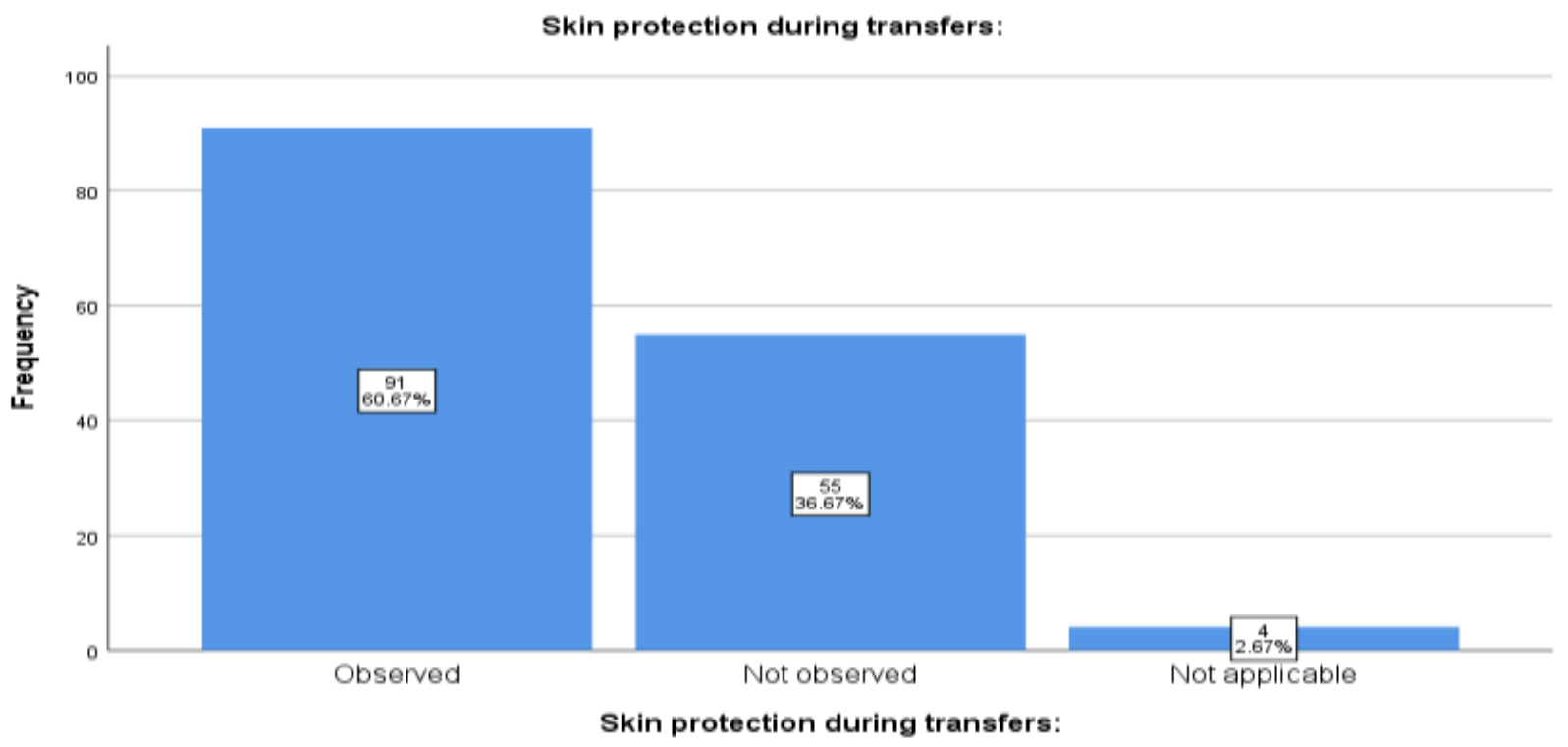

Figure 17

Figure 18 shows that the assessment results regarding Item eleven which is "Changing positions and turning" and results revealed that the $94(62.3 \%)$ were observed, $41(27.7 \%)$ were observed and only $15(10 \%)$ observed as not applicable while give care to the patients. 


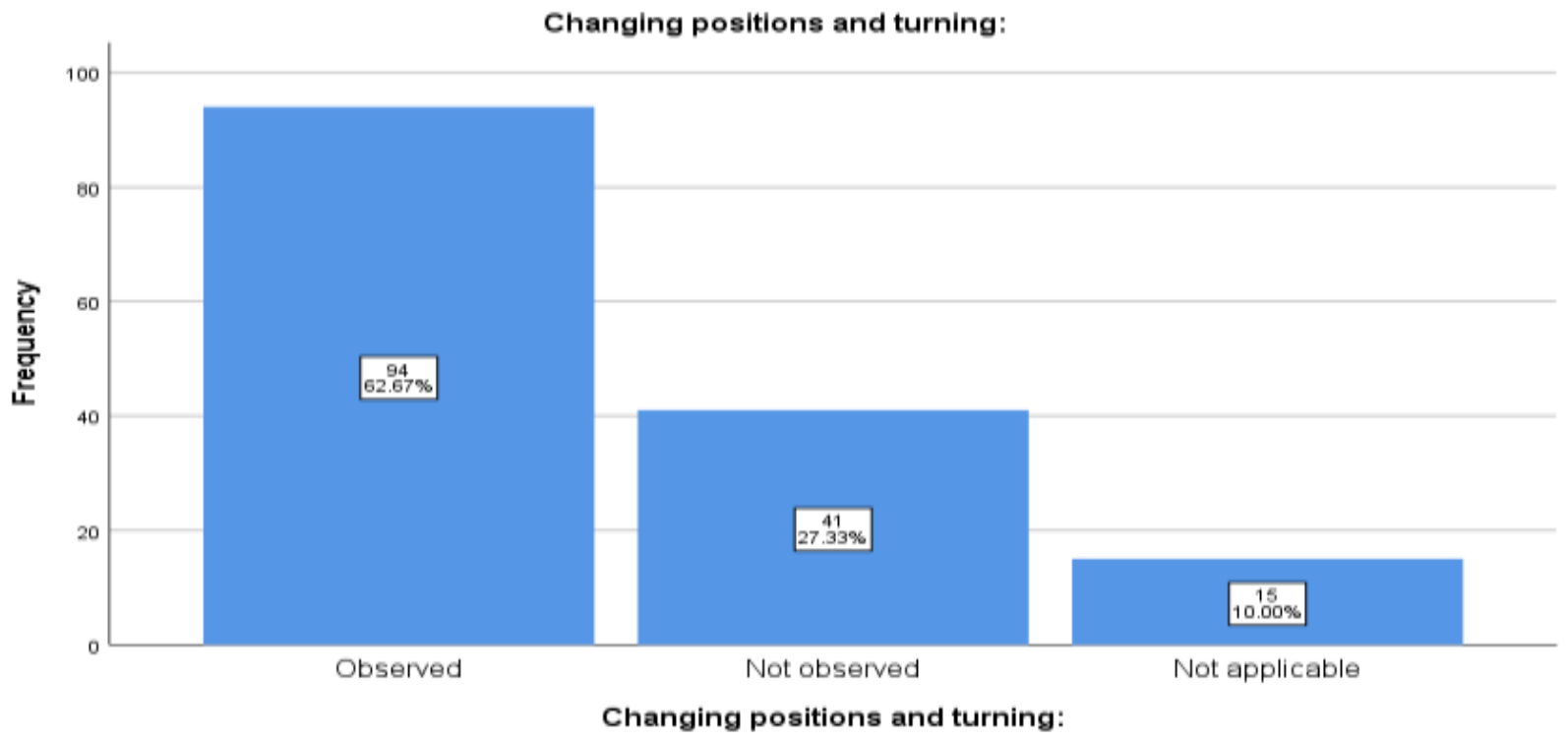

Figure 18

Figure 19 shows that the results of Item twelve which is "Recording the nursing interventions and its results" and results revealed that the $87(58 \%)$ were observed, $52(34.7 \%)$ were not observed and only $11(7.3 \%)$ were observed as not applicable regarding decubitus ulcer prevention.

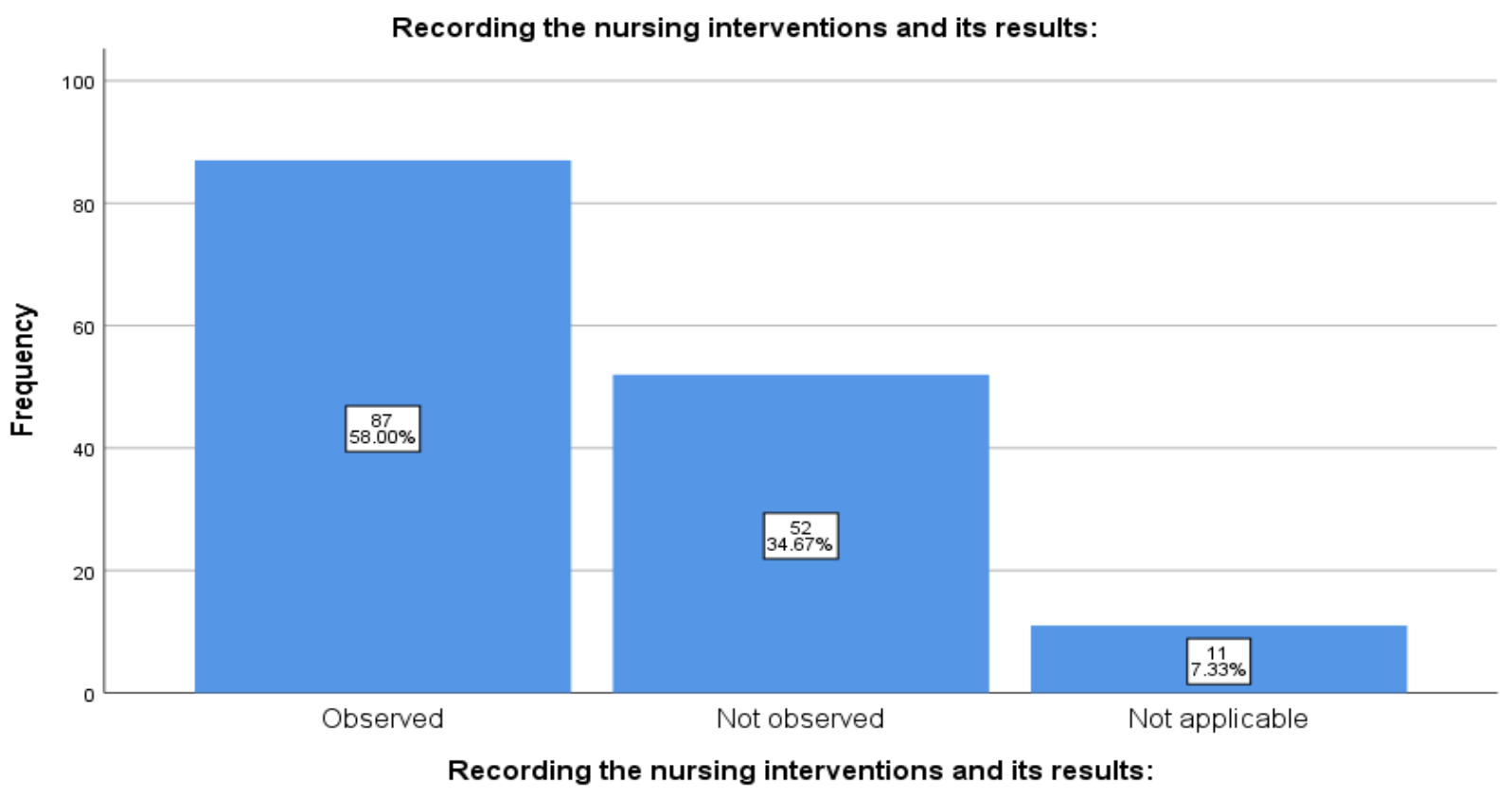

Figure 19

Figure 20 shows that the observation regarding item thirteen of checklist and results revealed that the 105 (70\%) were observed as repositioning, $26(17.3 \%)$ were not observed and only $19(12.3 \%)$ assess as not applicable while giving care to the patients regarding prevention of pressure ulcer. 


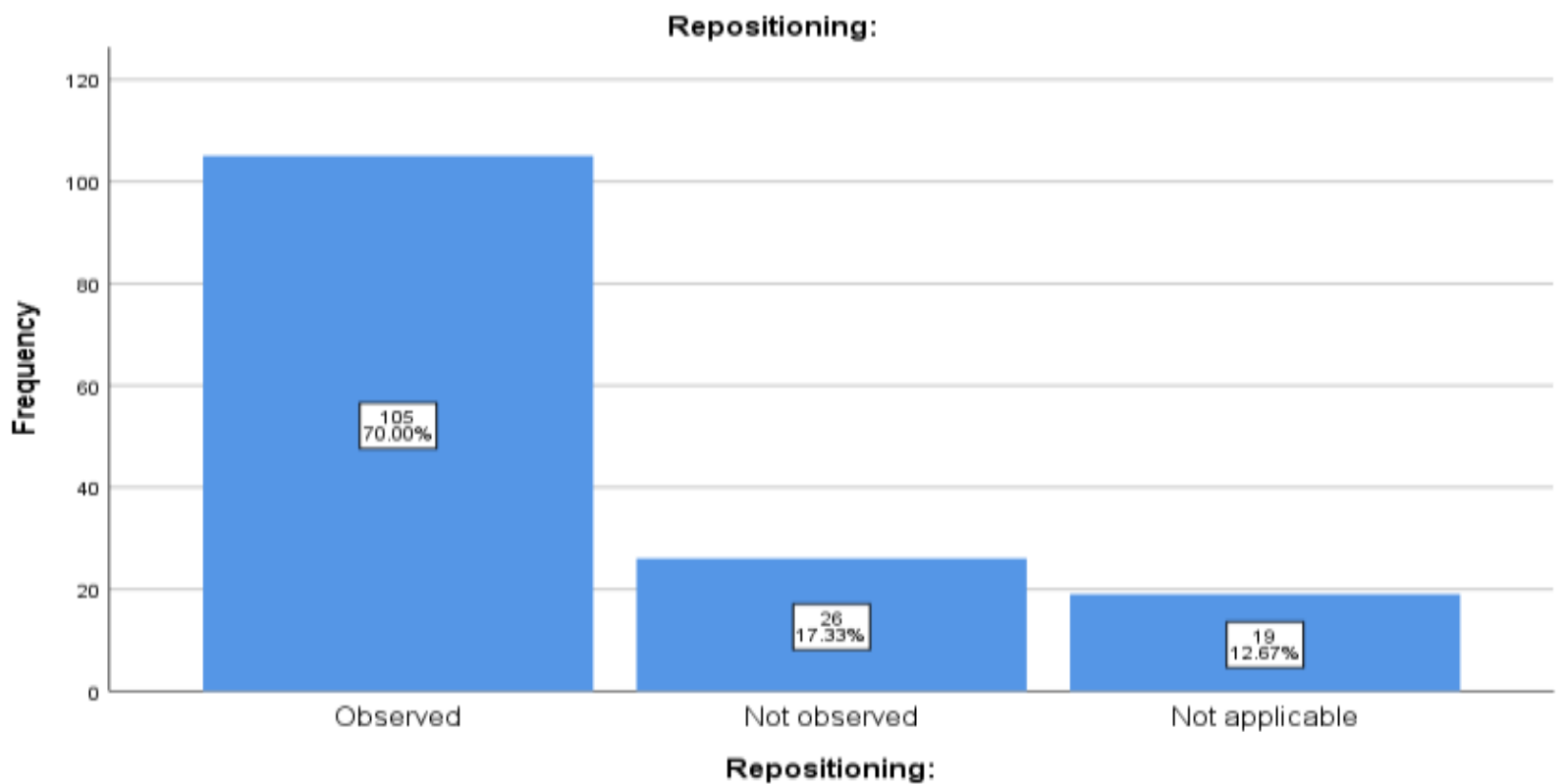

Figure 20

Figure 21 shows that the results of Item fourteen which is "Use of a chart for changing position and turning:" and results revealed that the $95(63 \%)$ were observed, 48 (32.3\%) were observed and only $7(4.7 \%)$ observed as not applicable while give care to the patients.

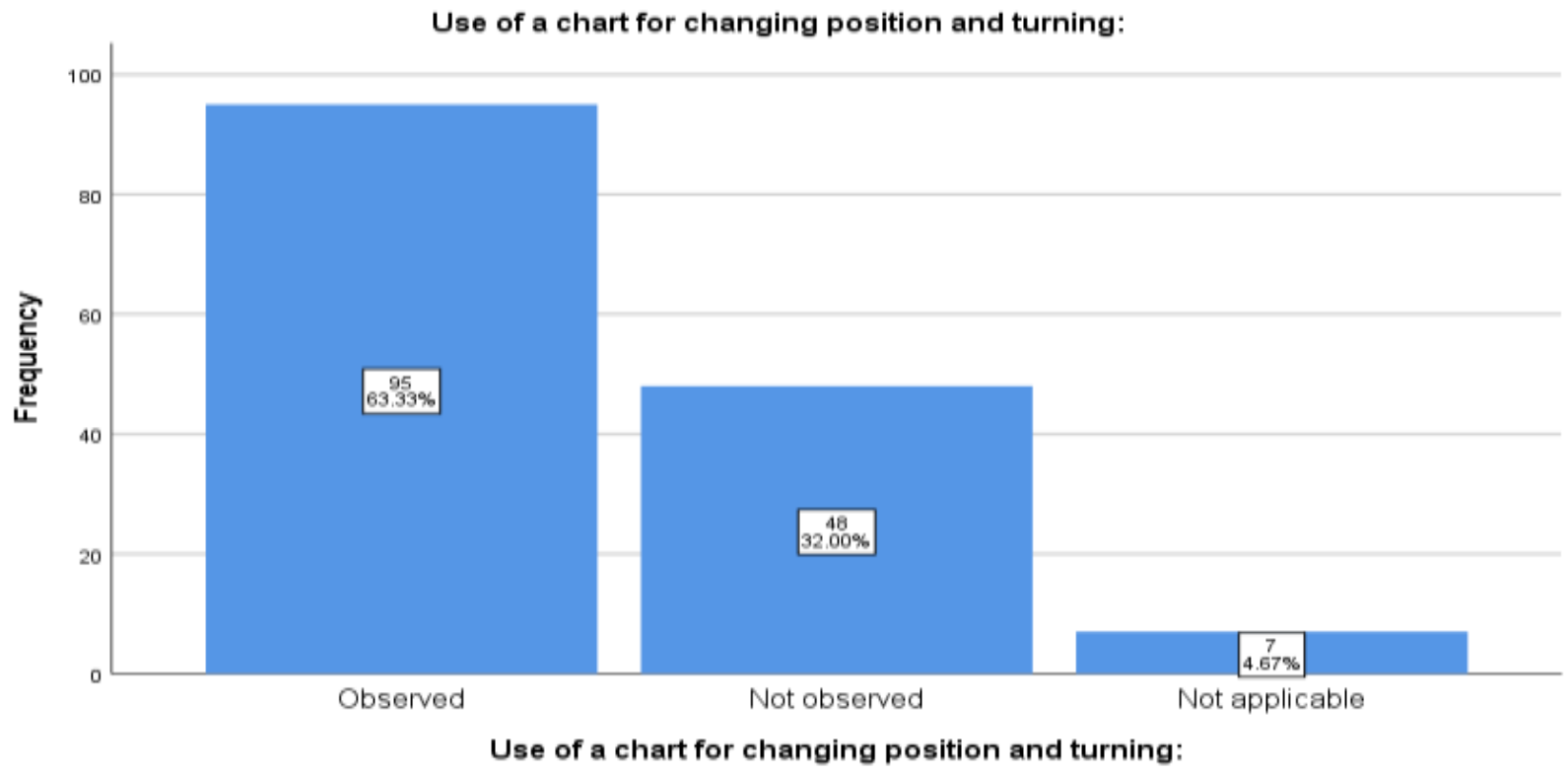

Figure 21

Figure 22 shows that the results of Item fifteen which is Item fifteen is "Using devices to prevent contact." and results revealed that the $100(66 \%)$ were observed, $39(26.7 \%)$ were not observed and only $11(7.3 \%)$ were observed as not applicable regarding decubitus ulcer prevention. 


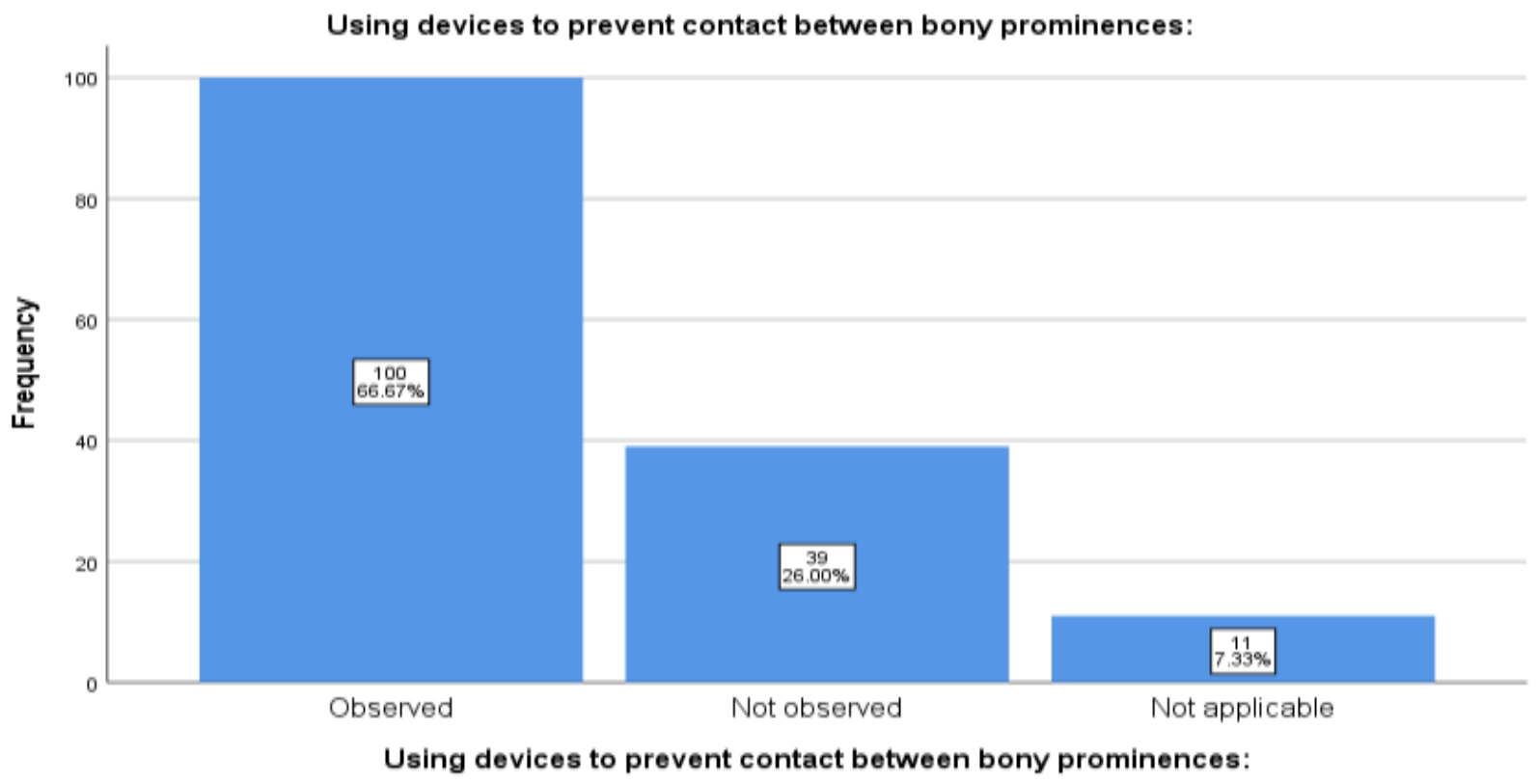

Figure 22

Figure 23 shows that the observation regarding item sixteen of checklist and results revealed that the $116(77.3 \%)$ were observed as heels lifted to decrease pressure, 29 (19.3\%) were not observed and only $5(3.3 \%)$ assess as not applicable while giving care to the patients regarding prevention of pressure ulcer.

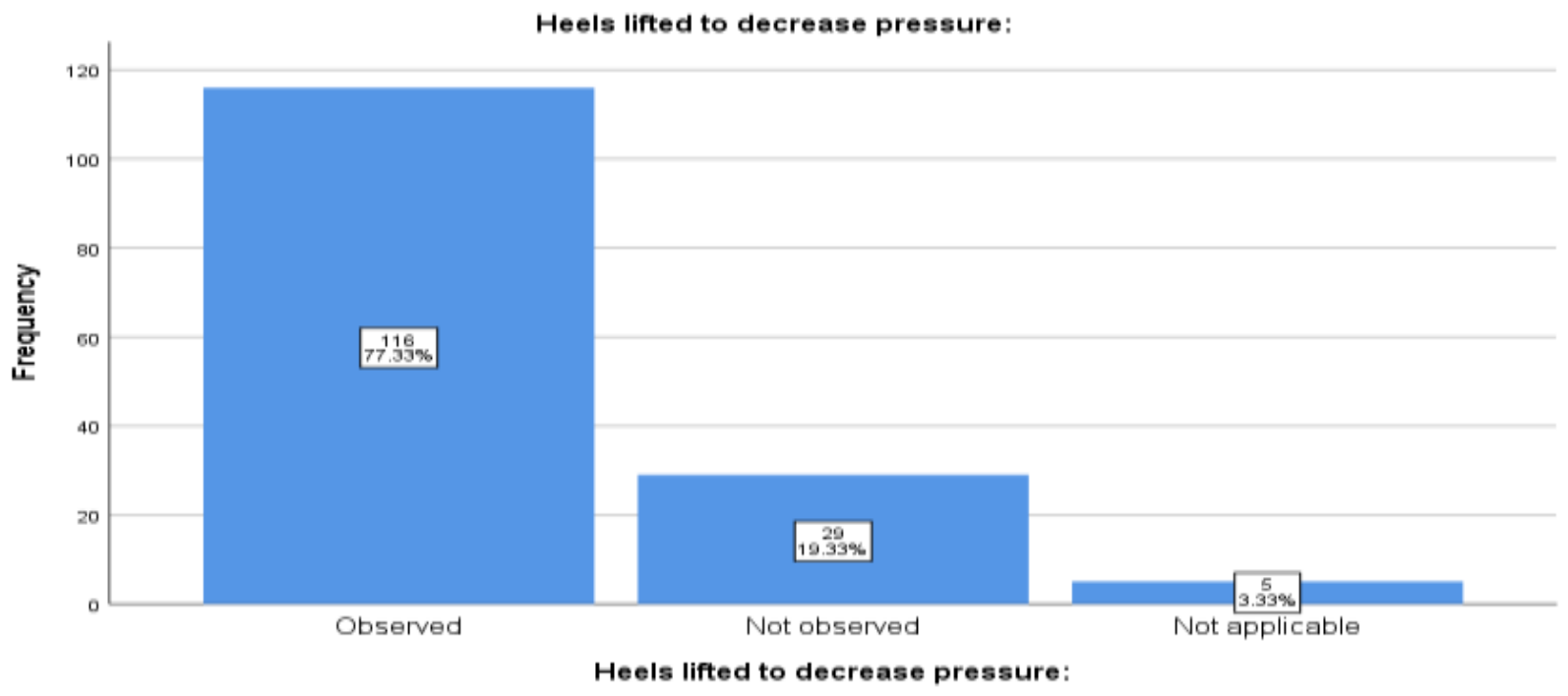

Figure 23

Figure 24 shows that the results of Item seventeen which is "Minimizing the period in which the head of the bed tilted more than 30 degrees" and results revealed that the $101(67.3 \%)$ were observed, 35 (23.3\%) were observed and only $14(9.3 \%)$ observed as not applicable while give care to the patients. 


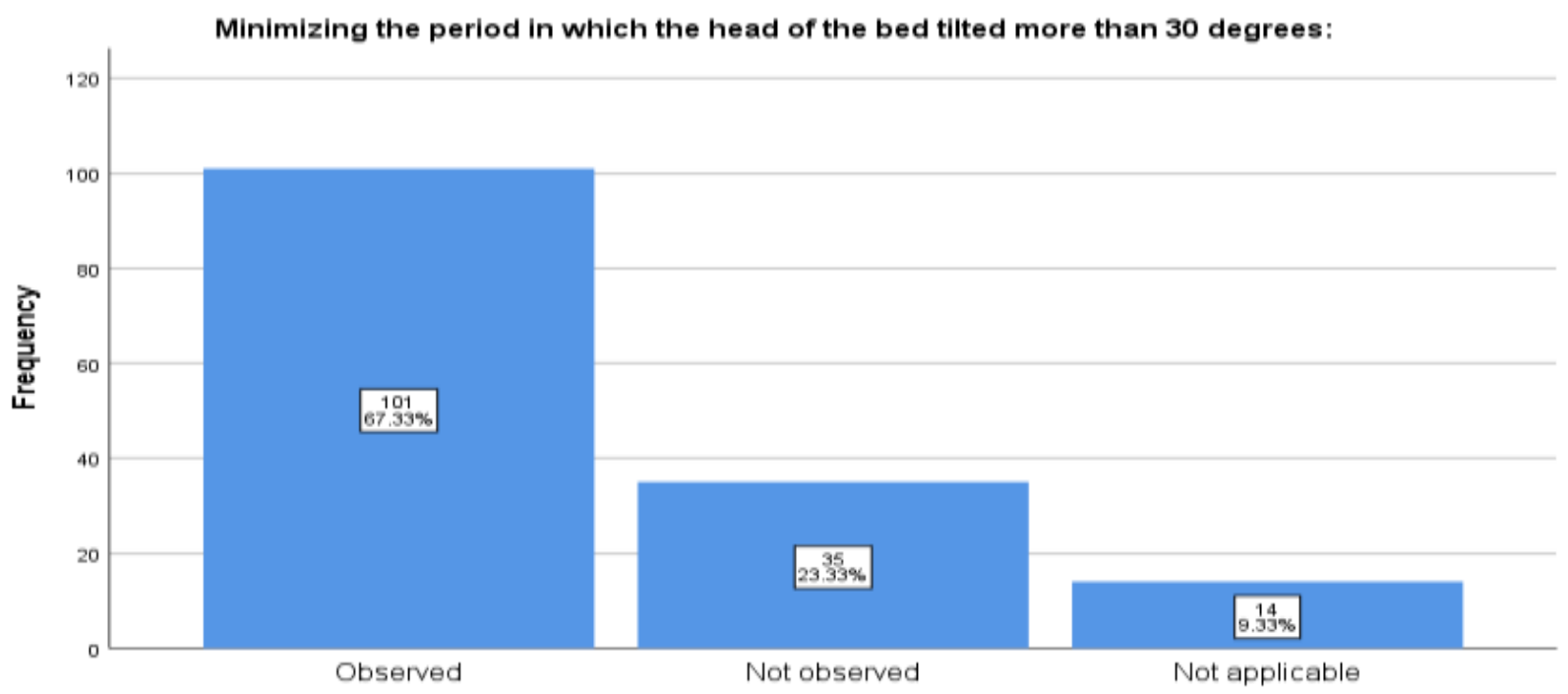

Minimizing the period in which the head of the bed tilted more than 30 degrees:

Figure 24

Figure 25 shows that the results of item eighteen which is "Patient mobilized (where possible) Use of pressure relieving mattress" and results revealed that the $87(58 \%)$ were observed, $40(26.7 \%)$ were not observed and only 23 $(15.3 \%)$ were observed as not applicable regarding decubitus ulcer prevention.

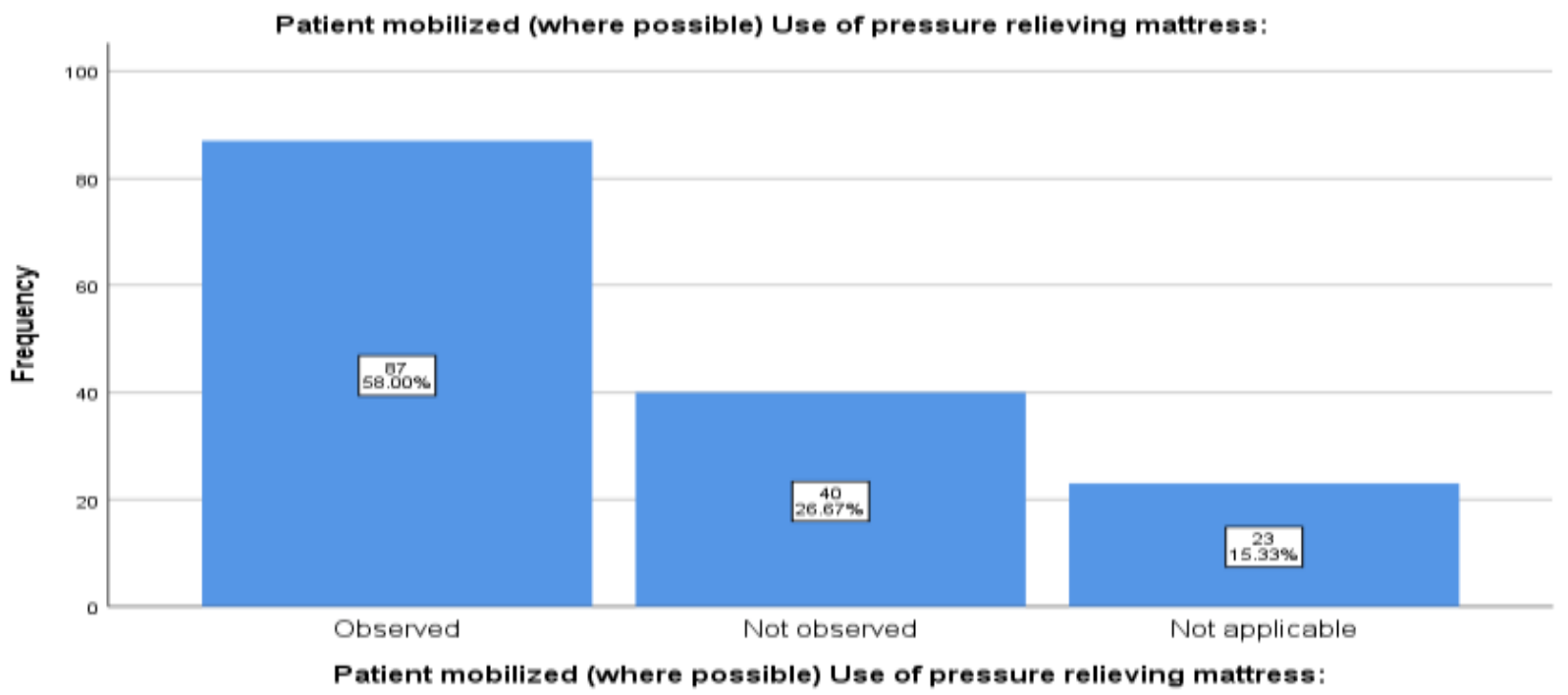

Figure 25

Figure 26 shows that the the observation regarding item nineteen of checklist and results revealed that the 96 (64\%) were observed as taught how to reposition themselves when sitting on the chair, $44(29.3 \%)$ were not observed and only $10(6.7 \%)$ assess as not applicable while giving care to the patients regarding prevention of pressure ulcer. 


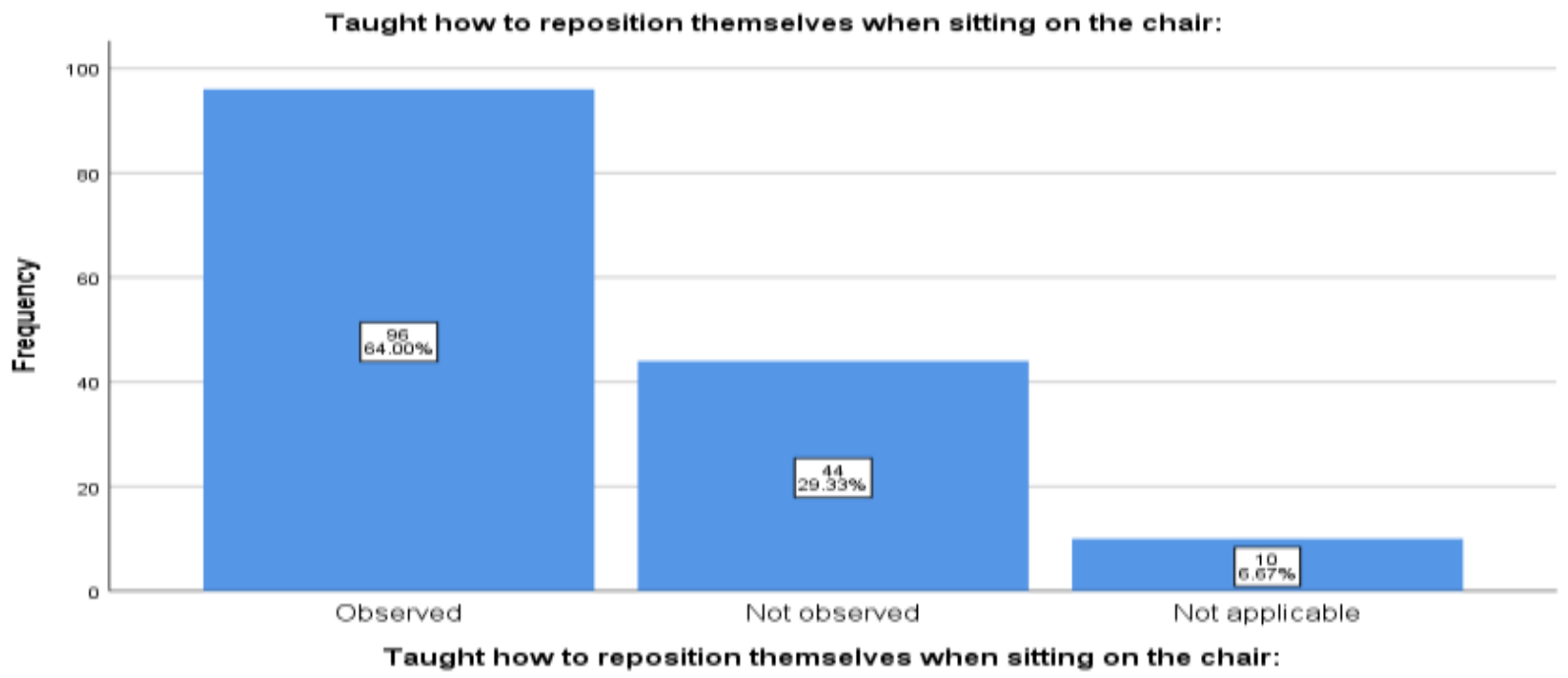

Figure 26

Figure 27 shows that the observation regarding item twenty of checklist and results revealed that the 106 (70.6\%) were observed as when sitting on the chair position changed every hour or transferred to bed, $27(18 \%)$ were not observed and only $17(11.4 \%)$ assess as not applicable while giving care to the patients regarding prevention of pressure ulcer.

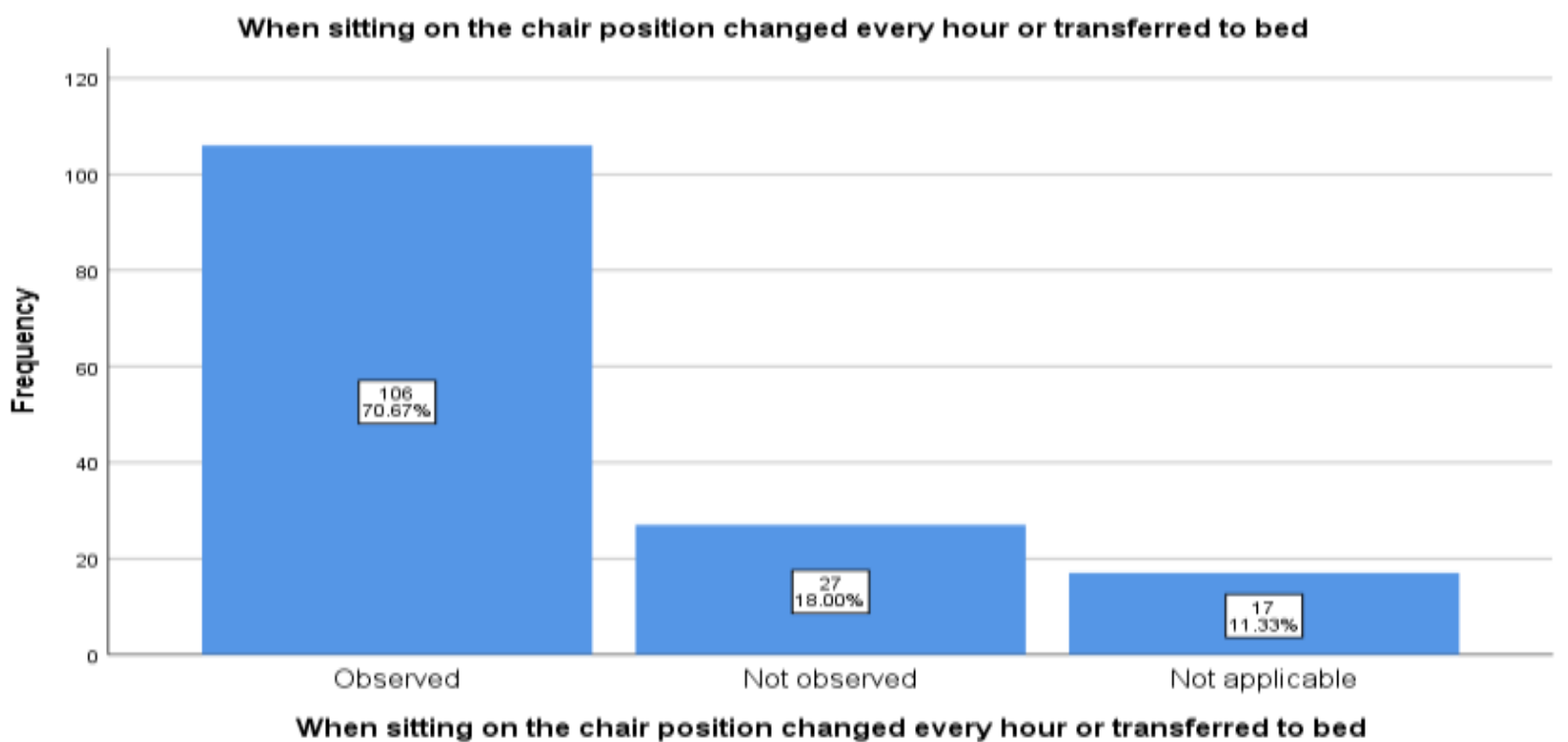

Figure 27

Figure 28 shows that the results of item twenty-one which is "Use of pressure relieving devices on chairs" and results revealed that the $96(64 \%)$ were observed, 39 (26.7\%) were not observed and only $15(10 \%)$ were observed as not applicable regarding decubitus ulcer prevention. 


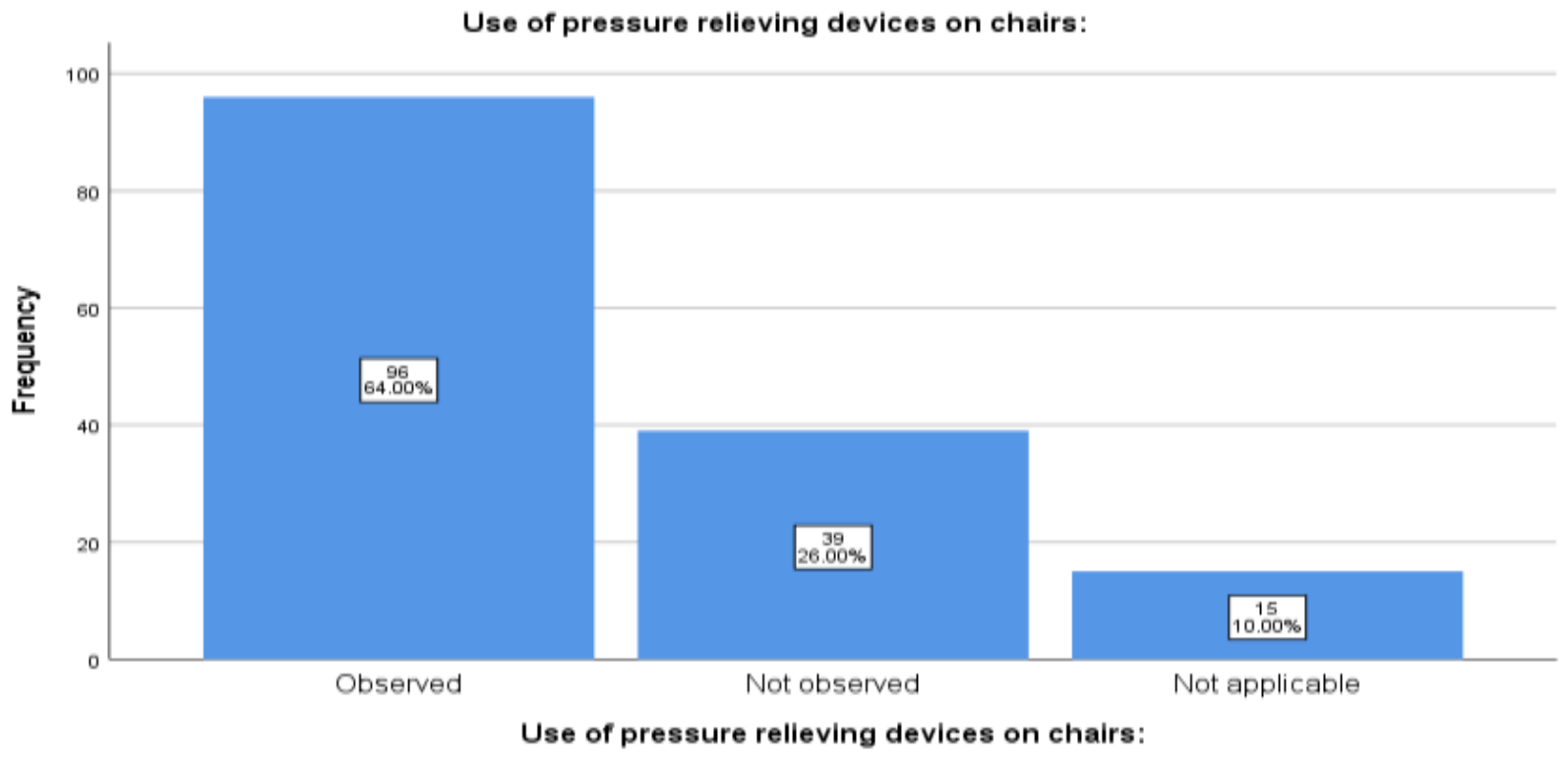

Figure 28

Figure 29 shows that the results of item twenty-two which is "Nutritional assessment" and results revealed that the $102(68 \%)$ were observed, $36(24 \%)$ were not observed and only $12(8 \%)$ were observed as not applicable regarding decubitus ulcer prevention.

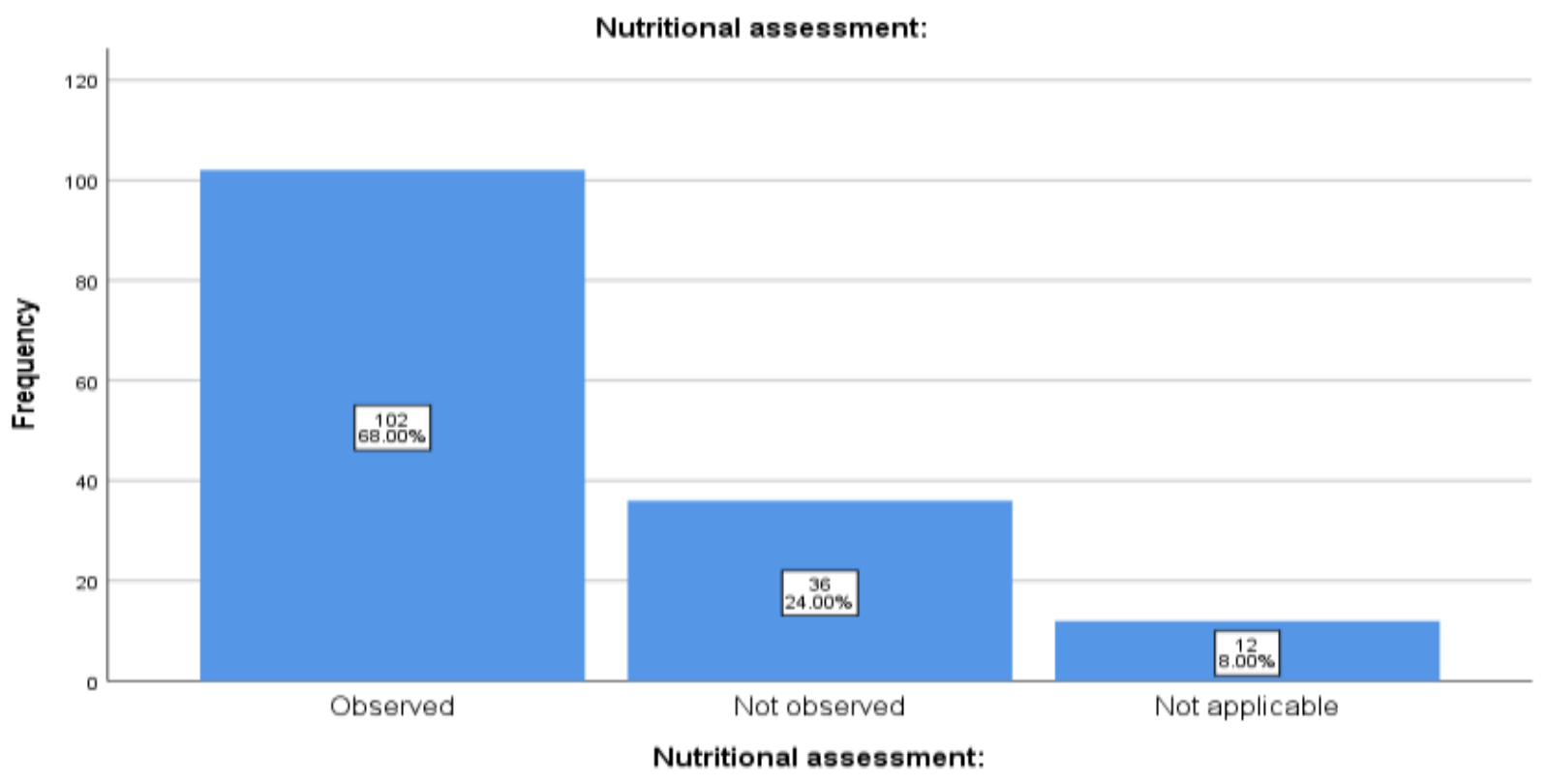

Figure 29

Figure 30 shows that the results of item twenty-three which is "Assisted with eating and drinking" and results revealed that the 77 (51.3\%) were observed, 41 (27\%) were not observed and only $32(21 \%)$ were observed as not applicable regarding decubitus ulcer prevention. 


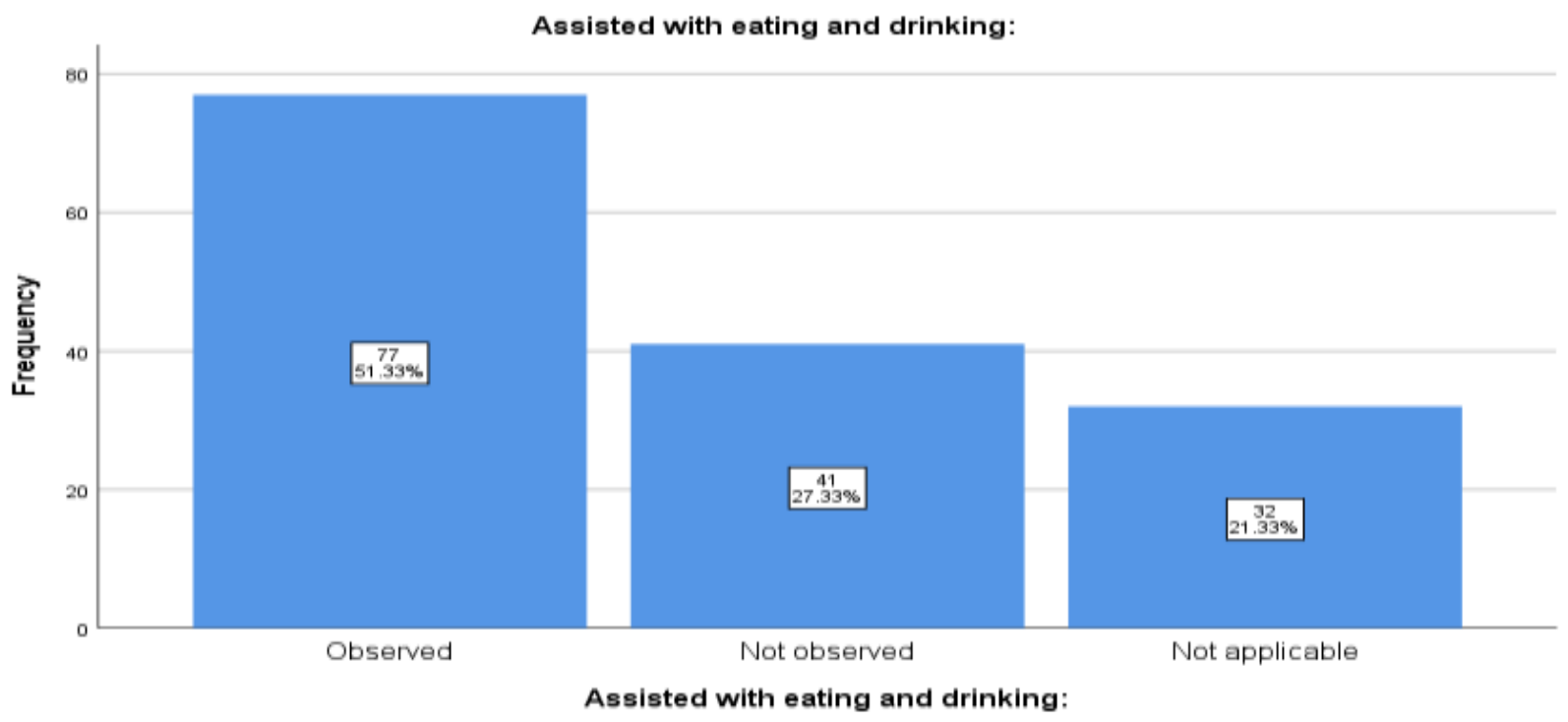

Figure 30

Figure 31 shows that the results of item twenty-four which is "Recording of nutritional assessment" and results revealed that the $86(57.3 \%)$ were observed, $44(29.3 \%)$ were not observed and only $20(13.3 \%)$ were observed as not applicable regarding decubitus ulcer prevention.

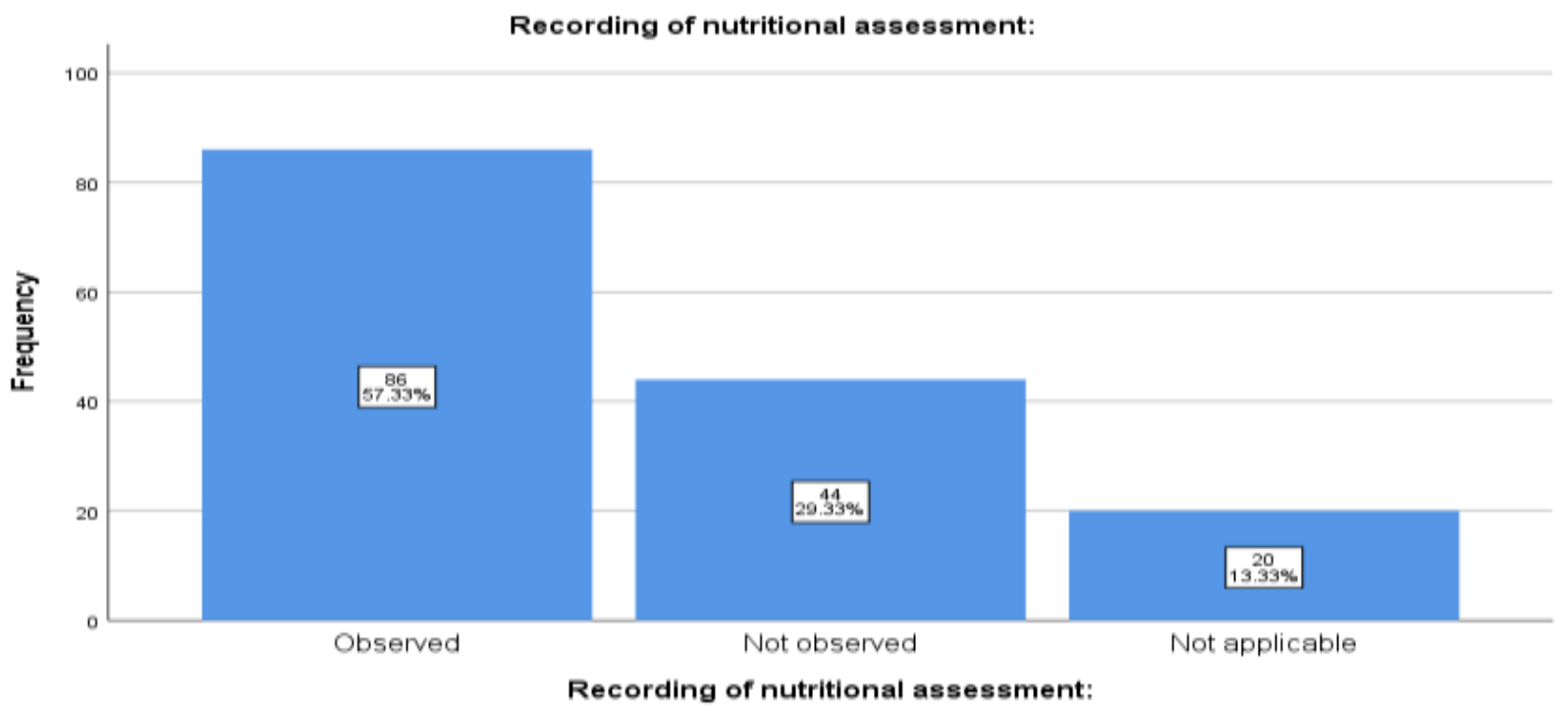

Figure 31

Figure 32 shows that the results of item twenty-five which is "Patients given information on the prevention of pressure sores" and results revealed that the $52(34 \%)$ were observed, $74(49.3 \%)$ were not observed and only $24(16.7 \%)$ were observed as not applicable regarding decubitus ulcer prevention. 


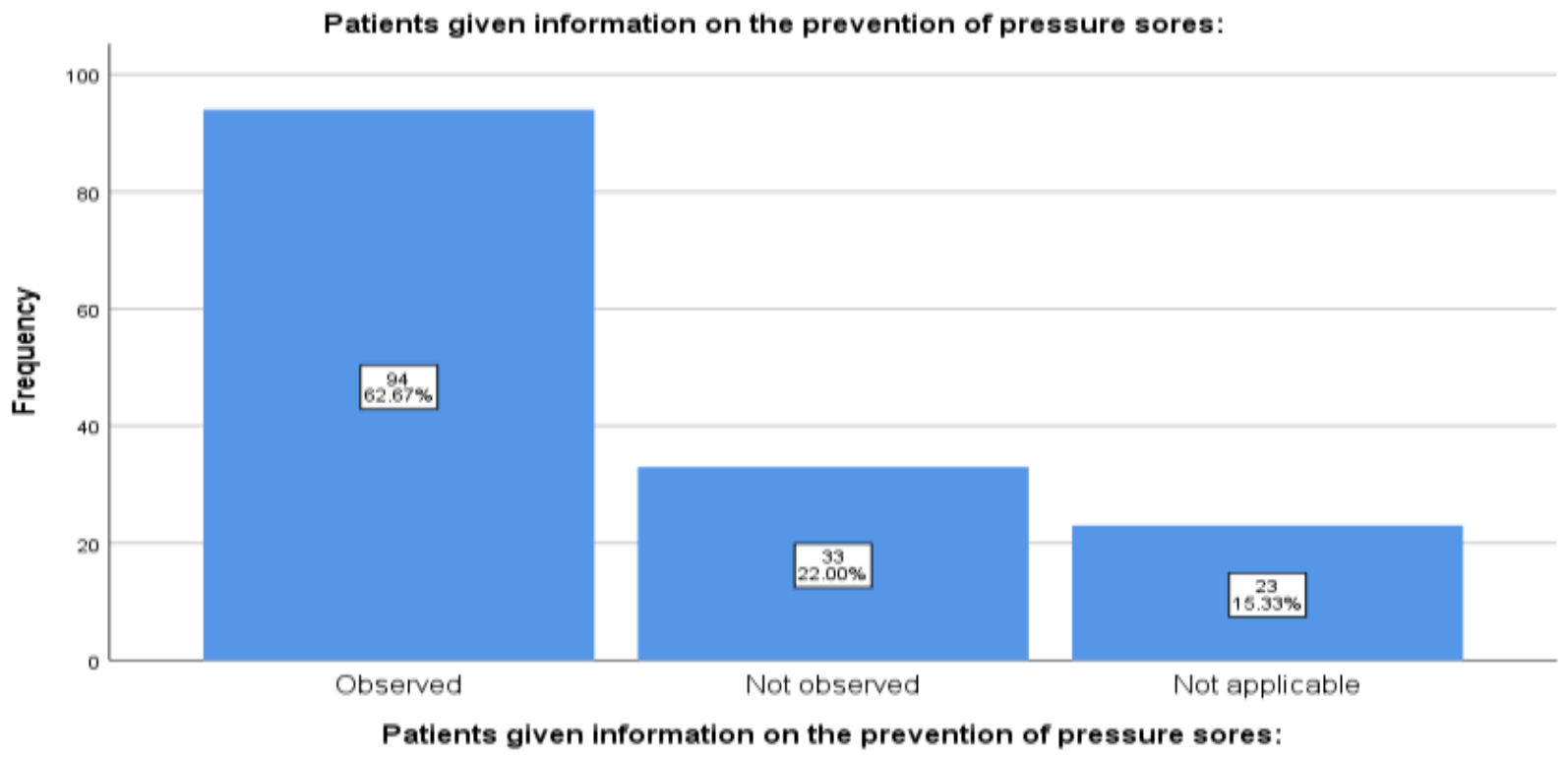

Figure 32

Figure 33 shows that the observation regarding item twenty-six of checklist and results revealed that the 75 (50\%) were observed as relatives given information on the prevention of pressure sores, 53 (35.3\%) were not observed and only $22(14.6 \%)$ assess as not applicable while giving care to the patients regarding prevention of pressure ulcer.

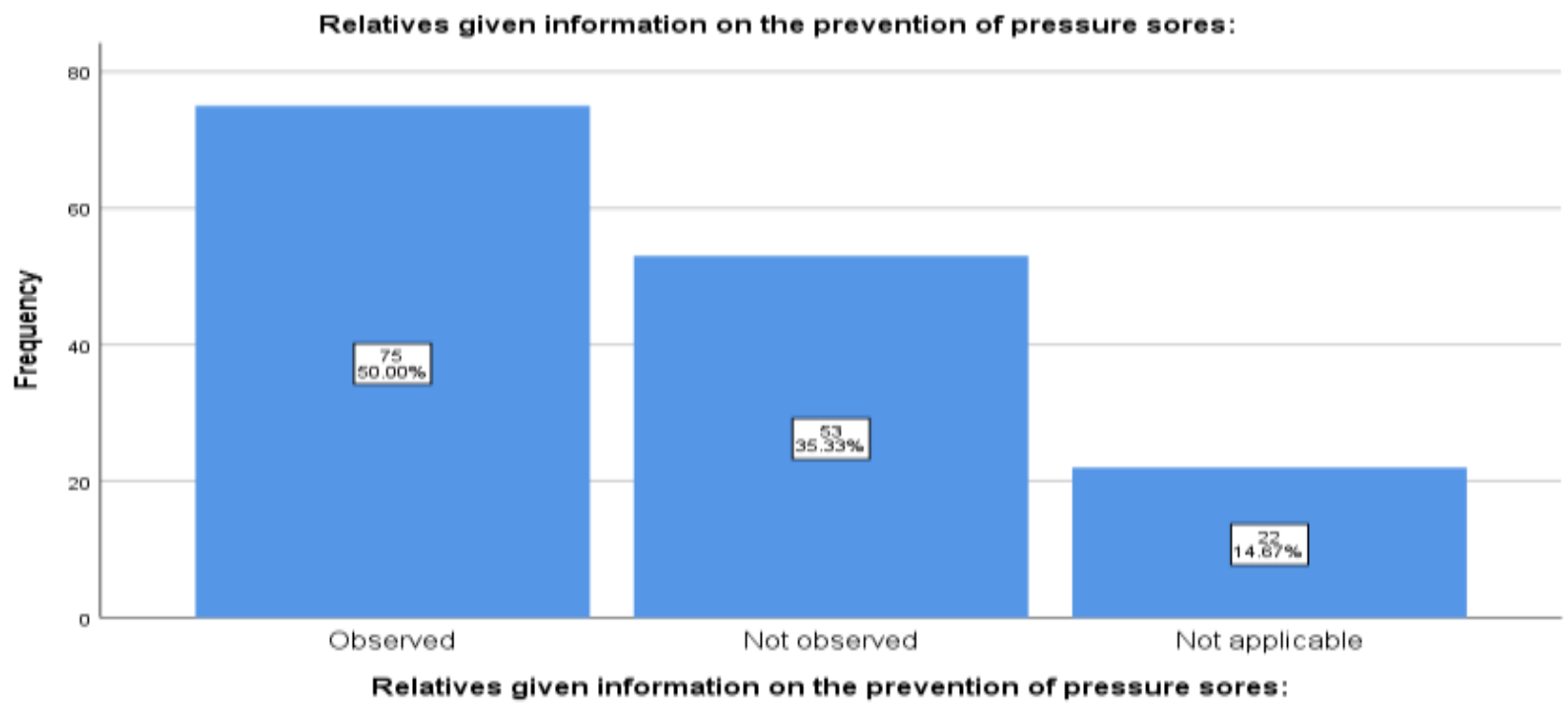

Figure 33

Figure 34 shows that the observation regarding item twenty-seven of checklist and results revealed that the 52 (34.6\%) were observed as Support staff given information on the prevention of pressure sores, $74(49.4 \%)$ were not observed and only $24(16 \%)$ assess as not applicable while giving care to the patients regarding prevention of pressure ulcer. 


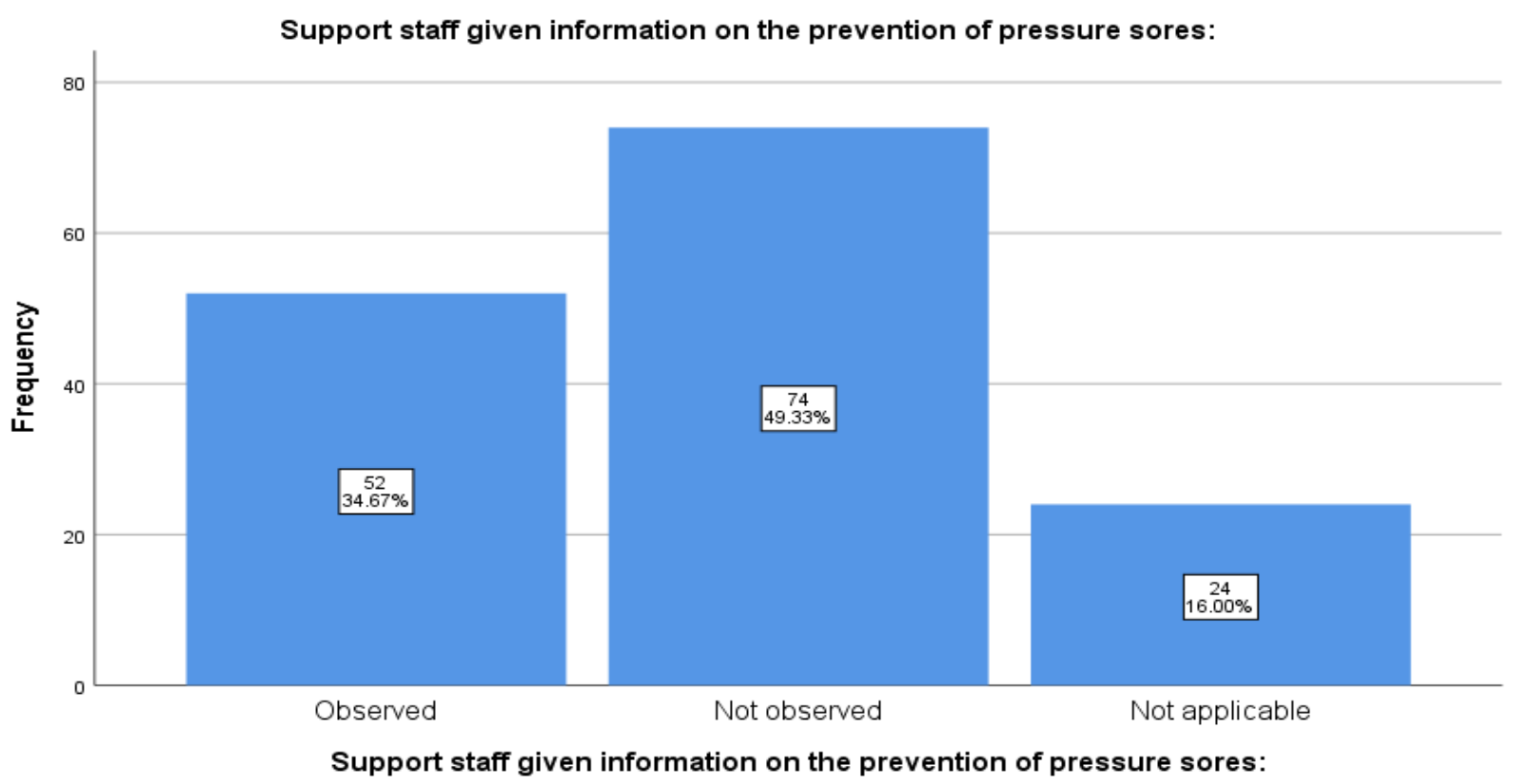

Figure 34

\section{CHAPTER - IV \\ DISCUSSION}

The results revealed that the gender of the participants was found $80(53.3 \%)$ male and $70(46.7 \%)$ were female. Age of participants was found minimum 21 to highest 60, participant's age group 21-30 years frequency was 11 (7.3\%), moderately 44 (29.3\%) participants were belong to age group 31-40 years and $33(22.1 \%)$ were fall in age group 4150 years and majority $62(42.3 \%)$ were 51-60-year-old. Only 37 (24.7\%) participants have not previously hospitalised and majority $113(75,3 \%)$ previously hospitalised. Participants' type of the ward as expected was majority 89 (59.3\%) admitted in critical care units, only $23(15.3 \%)$ admitted in medical wards and $38(25.3 \%)$ were admitted in surgical ward.

The length of stay (days) in hospital of the participants was found as $22(14.3 \%)$ were stayed in hospital for 1-10 days, $43(28.3 \%)$ were stay for 11-20 days, majority $53(35.2 \%)$ were stay $21-30$ days and $32(21.2 \%)$ stay for 31 or more than 31 days. Assessment regarding history of pressure ulcer and results revealed that majority 78 (52\%) have not previous history of ulcer and $72(48 \%)$ have previous history of ulcer. Observation regarding presence of pressure 
ulcers, and results revealed that $92(61.3 \%)$ have pressure ulcer at the time of study and $58(38.7 \%)$ have not ulcer at the time of study.

In this study results that nurses have poor practices $66(44.1 \%)$ regarding risk factors of pressure ulcer development, patient's position every two hourly $105(70 \%)$ but in contrast another study conducted in Bangladesh which result shows that nurse's practices about factors related to pressure ulcer, was at very low to low level (Islam, Sae-Sia, \& Khupantavee, 2010). But the study of Uganda revealed that nurses knowledge about frequent patient positioning can protect patient from pressure ulcers was $(98.2 \%)$, risk factors which can cause pressure ulcer in bedridden patients was $92.9 \%$, prolong positioning $83.9 \%$ (Mwebaza et al., 2014).

This study finding shows that nurses practices are poor $52(34 \%)$ and $52(34.6 \%)$ in order to give pressure ulcer prevention education to patient's and caregivers but the study conducted in Aydr referral hospital result shows that nurses practices regarding education of patients and care givers were $90.1 \%$ which was much higher than us (Yitayih, Panerio, \& Molla, 2019).

From this current study one of what mostly nurses never do is documentation of all data related to Pressure ulcer development $86(57.3 \%)$ for nutritional assessment record, "Recording the nursing interventions and its results" and results revealed that the $87(58 \%)$ were observed and use devices to prevent ulcer is $96(64 \%)$. But in contrast this study revealed the results regarding nurses practices of pressure ulcer prevention that (16.6\%) use assessment scale, that is very low then Ethiopian nurses, nurses who using air mattress for patients who are at high risk for pressure ulcer development $(23.3 \%)$, and only $(22.5 \%)$ nurses document all data regarding to pressure ulcer assessment which is even lower then Ethiopian nurses practices (Nasreen et al., 2017).

Indicates practice Frequency and percentage as per questionnaire. Total 150 participants attended 27 test items. $60 \%$ showed good practices towards prevention of pressure ulcer. A similar study conducted by Nurhusien Nuru find out as Nearly half ( $48.4 \%$ ) of the respondents had a good practice; whereas the remaining $51.6 \%$ respondents had a poor practice of pressure ulcer prevention (Nuru et al., 2015). Above 50\% participants always practice for test item no.5,15 on skin care, use comfort devices and more attention on a pressure point. As well as 108(56\%) participants were performing skin assessment for pressure ulcer. $52(34.6 \%)$ never gave advice to the caregiver about a use of creams for prevention of pressure ulcer.

Conclusion: This study was conducted to assess level of nurses' practice towards pressure ulcer prevention. Generally, the study showed that: Nurses' overall practice regarding pressure ulcer prevention was poor. Education can bring a change in individual behavior so change in knowledge can influence the practices. So, nurses need to get continuing education and training about pressure ulcer prevention that will enhance their knowledge and practices. Further researches about pressure ulcer prevention are needed.

Recommendation: Training programs should be conducted about pressure ulcer prevention for nurses who are working in hospital. • Results of the study should be disseminated and shared with the administration including nurse administrator, hospital administration. - Practices of nurses regarding pressure ulcer prevention not only enough without utilization of standards protocols into practices while caring of patients.

Acknowledgment: My sincere thanks extend to all nurses participated in the study and data collection facilitators with their respective hospitals who paid great contribution for facilitating data collection. 


\section{References:}

Ashour, D. S. (2019). Ivermectin: from theory to clinical application. International journal of antimicrobial agents.

Badran, I. G. (1995). Knowledge, attitude and practice the three pillars of excellence and wisdom: a place in the medical profession.

Black, J., Baharestani, M. M., Cuddigan, J., Dorner, B., Edsberg, L., Langemo, D., . . Taler, G. (2007). National Pressure Ulcer Advisory Panel's updated pressure ulcer staging system. Advances in skin \& wound care, 20(5), 269-274.

Coyer, F., \& Tayyib, N. (2017). Risk factors for pressure injury development in critically ill patients in the intensive care unit: a systematic review protocol. Systematic reviews, 6(1), 58.

Dilie, A., \& Mengistu, D. (2015). Assessment of nurses' knowledge, attitude, and perceived barriers to expressed pressure ulcer prevention practice in Addis Ababa government hospitals, Addis Ababa, Ethiopia, 2015. Advances in Nursing, 2015.

Esan, D. T., Fasoro, A. A., Ojo, E. F., \& Obialor, B. (2018). A descriptive, cross-sectional study to assess pressure ulcer knowledge and pressure ulcer prevention attitudes of nurses in a tertiary health institution in Nigeria. Ostomy Wound Management, 64(6), 24-28.

Gage, W. (2015). Preventing pressure ulcers in patients in intensive care. Nursing Standard (2014+), 29(26), 53.

Islam, S., Sae-Sia, W., \& Khupantavee, N. (2010). Knowledge, attitude, and practice on pressure ulcer prevention among nurses in Bangladesh. Paper presented at the The 2nd International Conference on Humanities and Social Sciences.

Kaddourah, B., Abu-Shaheen, A. K., \& Al-Tannir, M. (2016). Knowledge and attitudes of health professionals towards pressure ulcers at a rehabilitation hospital: a cross-sectional study. BMC nursing, 15(1), 17.

Kim, J. K., Yoo, S. H., Nho, J. H., \& Ju, J. K. (2019). Performance and Influencing Factors of Evidence-Based Pressure Ulcer Care Among Acute Care Hospital Nurses. Worldviews on Evidence-Based Nursing, 16(1), 29-35.

Mahalingam, S., Gao, L., Nageshwaran, S., Vickers, C., Bottomley, T., \& Grewal, P. (2014). Improving pressure ulcer risk assessment and management using the Waterlow scale at a London teaching hospital. Journal of wound care, 23(12), 613-622.

Martin, D., Albensi, L., Van Haute, S., Froese, M., Montgomery, M., Lam, M., . . Basova, N. (2017). Healthy skin wins: a glowing pressure ulcer prevention program that can guide evidence-based practice. Worldviews on Evidence-Based Nursing, 14(6), 473-483.

McInnes, E., Jammali-Blasi, A., Bell-Syer, S. E., Dumville, J. C., Middleton, V., \& Cullum, N. (2015). Support surfaces for pressure ulcer prevention. Cochrane Database of Systematic Reviews(9).

Muhammad, D., Ahmad, I. W., Khan, M. N., Ali, F., \& Muhammad, G. KNOWLEDGE, ATTITUDE AND PRACTICES OF NURSES REGARDING PRESSURE ULCERS PREVENTION AT A TERTIARY CARE HOSPITAL OF PESHAWAR, KHYBER PAKHTUNKHWA. Cell, 333, 9482238.

Mwebaza, I., Katende, G., Groves, S., \& Nankumbi, J. (2014). Nurses' knowledge, practices, and barriers in care of patients with pressure ulcers in a Ugandan teaching hospital. Nursing research and practice, 2014.

Nasreen, S., Afzal, M., \& Sarwar, H. (2017). Nurses knowledge and practices toward pressure ulcer prevention in general hospital Lahore. Age, 87(166), 34.34.

Nuru, N., Zewdu, F., Amsalu, S., \& Mehretie, Y. (2015). Knowledge and practice of nurses towards prevention of pressure ulcer and associated factors in Gondar University Hospital, Northwest Ethiopia. BMC nursing, 14(1), 34.

Saghaleini, S. H., Dehghan, K., Shadvar, K., Sanaie, S., Mahmoodpoor, A., \& Ostadi, Z. (2018). Pressure ulcer and nutrition. Indian journal of critical care medicine: peer-reviewed, official publication of Indian Society of Critical Care Medicine, 22(4), 283.

Shanley, E., Moore, Z., Patton, D., Connor, T. O., Avsar, P., Nugent, L., \& Beeckman, D. (2019). Development and psychometric evaluation of the patient knowledge of, and attitudes and behaviours towards pressure ulcer prevention instrument (KPUP). International Wound Journal.

Shrestha, R. (2017). knowledge and practices of bed sore prevention among staff nurses working in a selected hospital ludhiana punjab india. International Journal of Experimental and Clinical Research.

Stansby, G., Avital, L., Jones, K., \& Marsden, G. (2014). Prevention and management of pressure ulcers in primary and secondary care: summary of NICE guidance. $B m j, 348$, g2592.

Stephens, M., \& Bartley, C. (2018). Understanding the association between pressure ulcers and sitting in adults what does it mean for me and my carers? Seating guidelines for people, carers and health \& social care professionals. Journal of tissue viability, 27(1), 59-73. 
Taylor, C. (2017). Importance of nutrition in preventing and treating pressure ulcers. Nursing older people, 29(6).

Teague, L., Mahoney, J., Goodman, L., Paulden, M., Poss, J., Li, J., . . . Krahn, M. (2011). Early prevention of pressure ulcers among elderly patients admitted through emergency departments: a cost-effectiveness analysis. Annals of emergency medicine, 58(5), 468-478. e463.

Yitayih, G., Panerio, W. G., \& Molla, M. (2019). Explore the Level of Awareness, Perception and Utilization of Pressure Ulcer Prevention among Health Professionals, Ayder Referral Hospital, 2013. Research \& Reviews: Journal of Oncology and Hematology, 5(1), 24-29. 